US Army Corps

of Engineers $\mathrm{B}_{\circledast}$

Engineer Research and

Development Center

Simultaneous Mapping of Coastal Topography and Bathymetry from a Lightweight Multicamera UAS

Katherine L. Brodie, Brittany L. Bruder, Richard K. Slocum,

August 2021

and Nicholas J. Spore 
The U.S. Army Engineer Research and Development Center (ERDC) solves the nation's toughest engineering and environmental challenges. ERDC develops innovative solutions in civil and military engineering, geospatial sciences, water resources, and environmental sciences for the Army, the Department of Defense, civilian agencies, and our nation's public good. Find out more at www.erdc.usace.army.mil.

To search for other technical reports published by ERDC, visit the ERDC online library at https://erdclibrary.on.worldcat.org/discovery. 


\section{Simultaneous Mapping of Coastal Topography and Bathymetry from a Lightweight Multicamera UAS}

Katherine L. Brodie, Brittany L. Bruder, and Nicholas J. Spore

Coastal and Hydraulics Laboratory

U.S. Army Engineer Research and Development Center

Field Research Facility

3909 Halls Ferry Road

Vicksburg, MS 39180

Richard K. Slocum

School of Civil and Construction Engineering

Oregon State University

Corvallis, OR 97331

Final report

Approved for public release; distribution is unlimited.

Prepared for U.S. Army Corps of Engineers

Washington, DC 20134

Under Force Projection Entry Operations, STO D.GRD.2015.34 


\section{Preface}

This study was conducted for the U.S. Army Corps of Engineers USACE) and was supported in part by the Deputy Assistant Secretary of the Army for Research and Technology under ERDC's research program titled "Force Projection Entry Operations, STO D.GRD.2015.34," in part by the USACE Department of Homeland Security Emergency Management Office, in part by the USACE Flood and Coastal Systems Program, and in part by the USACE Coastal Ocean Data Systems Program.

The work was performed by the U.S. Army Engineer Research and Development Center, Coastal and Hydraulics Laboratory (ERDC-CHL), Field Research Facility in Duck, NC. At the time of publication of this paper, the Deputy Director of ERDC-CHL was Mr. Keith Flowers, and the Director was Dr. Ty V. Wamsley.

This paper was originally published in IEEE Transactions on Geoscience and Remote Sensing, 27 August 2019.

The Commander of ERDC was COL Teresa A. Schlosser and the Director was Dr. David W. Pittman.

DISCLAIMER: The contents of this report are not to be used for advertising, publication, or promotional purposes. Citation of trade names does not constitute an official endorsement or approval of the use of such commercial products. All product names and trademarks cited are the property of their respective owners. The findings of this report are not to be construed as an official Department of the Army position unless so designated by other authorized documents. 


\section{Simultaneous Mapping of Coastal Topography and Bathymetry From a Lightweight Multicamera UAS}

\begin{abstract}
A low-cost multicamera Unmanned Aircraft System (UAS) is used to simultaneously estimate open-coast topography and bathymetry from a single longitudinal coastal flight. The UAS combines nadir and oblique imagery to create a wide field of view (FOV), which enables collection of mobile, long dwell timeseries of the littoral zone suitable for structure-frommotion (SfM), and wave speed inversion algorithms. Resultant digital surface models (DSMs) compare well with terrestrial topographic lidar and bathymetric survey data at Duck, NC, USA, with root-mean-square error (RMSE)/bias of $0.26 /-0.05$ and $0.34 /-$ $0.05 \mathrm{~m}$, respectively. Bathymetric data from another flight at Virginia Beach, VA, USA, demonstrates successful compar-ison (RMSE/bias of $0.17 / 0.06 \mathrm{~m}$ ) in a secondary environment. UASderived engineering data products, total volume profiles and shoreline position, were congruent with those calculated from traditional topo-bathymetric surveys at Duck. Capturing both topography and bathymetry within a single flight, the presented multicamera system is more efficient than data acquisition with a single camera UAS; this advantage grows for longer stretches of coastline $(10 \mathrm{~km})$. Efficiency increases further with an on-board Global Navigation Satellite System-Inertial Navigation System (GNSS-INS) to eliminate ground control point (GCP) placement. The Appendix reprocesses the Virginia Beach flight with the GNSS-INS input and no GCPs. The resultant DSM products are comparable [root-mean-squared difference (RMSD)/bias of 0.
\end{abstract}

\section{INTRODUCTION}

$\mathbf{O}$ PEN coast topography and shallow bathymetry evolve rapidly in time and space in response to changing waves, currents, and water levels, necessitating frequent monitoring for accurate representation. Specifically, up-to-date knowledge of littoral topography and bathymetry (between +10 - and $-10-\mathrm{m}$ elevation above mean sea level) is important for a number of coastal applications, including forcing of numerical models forecasting storm impact on advance of hurricanes, assessment of beach nourishment project performance [1], or even for military personnel and vessels advancing over the shore [2]-[4]. Surveying approaches for seamlessly measuring littoral morphology have focused on the development of unique vessels, such as the Coastal Research Amphibious Buggy (CRAB [5]), a Lighter Amphibious Resupply Cargo Vessel (LARC) equipped with Real Time Kinematic Global Positioning System (RTK GPS) and an echosounder [6], and similar jet-ski-based systems [7] coupled with walking surveys [8]. These approaches often utilize collections of cross-shore transects spaced at set intervals along the shoreline. While the transects have high accuracy, errors may be introduced when reconstructing 3-D surfaces [9] and these approaches can be personnel, time, and equipment intensive, making them less accessible for frequent surveying. Remote sensing approaches have focused on airborne lidar, which can rapidly map 3-D coastal topography and bathymetry [10]-[12]. In optimal conditions, airborne lidar collects true seamless 3-D data of the littoral zone, but requires expensive sensors and large, manned planes for collection and can have limited effectiveness in penetrating the breaking, turbid waters of the shallow surf zone.

Over the last few decades, research has also focused on exploiting remote sensing observations of the water surface [13], utilizing the optical pixel intensity or radarbackscatter signals off the surface of shoaling or breaking waves, to map surf-zone morphology [14]-[17]. Multiple images over the same region are used to generate spatial timeseries of waves as they approach the shoreline. These timeseries can then be analyzed to map sandbar morphology [15], [18], and infer bathymetry from wave speed [16], [19], [20] or wave dissipation proxies [21]. These data can also be assimilated into numerical models to determine bathymetry [21]-[23] or predict other important littoral variables such as wave heights and currents [24]. While originally collected from shore-based stationary towers [14], these data have also been successfully collected from manned aircraft [16], [25], and more recently, from Unmanned Aircraft Systems (UAS) [2], [26]-[28]. One drawback to prior fixed wing UAS approaches are short dwell time-periods, which increases error in depth inversion results [2], [26]. The dwell time is increased with a higher flying altitude, larger sensor field of view (FOV), 
and/or slower aircraft speed. While multirotor UAS approaches solve the short-dwell problems by having the capability to hover in place, the survey region is reduced (e.g., $1=\mathrm{km}$ alongshore [28]). In addition, none of the aforementioned UAS approaches provided complementary observations of coastal topography, instead focusing solely on surf-zone morphology and bathymetry observations.

Classical photogrammetry reconstructs 3 -D topographic surfaces from overlapping aerial images [29] and has existed as a field for quite some time. Recent advances in computer vision software, in combination with availability of UAS [30], have led to the rapid rise in the use of newer Structure from Motion (SfM) [31] and multi-view stereo (MVS) algorithms to generate 3-D surfaces from imagery for geomorphic research [32]-[34]. SfM utilizes automated feature detection and matching algorithms on overlapping imagery of fixed objects to determine the 3-D structure of the scene in the form of a pointcloud, the camera interior orientation (IO), and the exterior orientation (EO) of the camera when each image was acquired. Additional information is required to convert the initial data from an arbitrary coordinate system to a user defined coordinate system. This information can be input via the use of photo identifiable ground control points (GCPs) with known coordinates or estimated coordinates for each image. These data are included as observations and implemented in a bundle adjustment to improve the reconstruction quality and convert the data to a known coordinate system. Surfaces generated from these UAS-based SfM approaches have been evaluated in a variety of environments from multirotor and fixed wing UAS [30], [32]-[35], and have been shown to be within $0.05 \mathrm{~m}$ [root-mean-squared error (RMSE) of $0.19 \mathrm{~m}$ ] when compared to terrestrial lidar observations over a $200-\mathrm{m}$ alongshore stretch of beach [33].

The objective of this paper is to demonstrate that coastal topography and bathymetry can be simultaneously estimated from video-imagery using structure-from-motion (SfM) and wave speed inversion algorithms applied to wide-FOV imagery from a single UAS-flight transiting along the coast. The presented system is tested at two field sites and utilizes multiple cameras to create a wide FOV, which enables collection of mobile, long dwell time-series by mixing nadir and oblique imagery. In Section II, we describe the development of the lightweight, inexpensive, multiple-camera sensor, associated timing and position system, and UAS testing platform. In Section III, we describe the data processing methodology and workflows. In Section IV, we provide information on the field sites and associated control data. In Section V, independent assessments of the orthophoto, topographic point cloud, and bathymetry data products are provided through comparisons to coincident stationary, tower-based imagery, vessel-based hydrographic surveys, and terrestrial lidar observations. In Section VI, we discuss the results and sources of error and highlight applications for the merged topobathymetric data, ending with a discussion on operations. The Appendix investigates the use of a high end Global Navigation Satellite System and Inertial Navigation System (GNSS-INS) with the multicamera system in lieu of GCPs and evaluates the differences in resultant data products.
TABLE I

Camera Tait-Bryan Angles (X-Y'-Z') And Image Parameters. Lens Distortion Models Are Defined in Agisoft [38]

\begin{tabular}{lllllll}
\hline \hline Camera & $\mathrm{X}\left[^{\circ}\right]$ & $\mathrm{Y}\left[^{\circ}\right]$ & $\mathrm{Z}\left[^{\circ}\right]$ & $\begin{array}{c}\text { FOCAL } \\
\text { LENGTH } \\
{[\mathrm{MM}]}\end{array}$ & $\begin{array}{c}\text { DISTORT } \\
\text {-ION } \\
\text { MODEL }\end{array}$ & $\begin{array}{c}\text { IMAGE SIZE } \\
\text { [PIXELS] }\end{array}$ \\
\hline Down & 180 & 0 & 90 & 5.5 & Frame & $3840 \times 2160$ \\
Side & 130 & 0 & 0 & 2.97 & Fisheye & $3840 \times 2160$ \\
Front & 0 & -125 & 0 & 2.97 & Fisheye & $3840 \times 2160$ \\
Back & 0 & 125 & 0 & 2.97 & Fisheye & $3840 \times 2160$ \\
\hline \hline
\end{tabular}

Lens distortion models are defined in Agisoft [38].

\section{SySTEM DESCRIPTION}

This effort utilized an X8+ quadcopter by 3DR Robotics [Fig. 1(a)] as a platform for data collection. The 3DR was selected for its small form factor (85-cm diagonal wingspan), low cost (U.S. \$1500), and large weight capacity $(1 \mathrm{~kg})$ for its size. The custom 3-D-printed multicamera payload was attached to the undercarriage of the platform via bolts and vibration dampening balls [Fig. 1(b)]. The 3-D-printed payload contains all of the components of the multicamera system (with the exception of a GPS antenna), and it is operated and powered independently of the $\mathrm{X} 8+$ hardware.

Specifically, the payload contains four GoPro Hero4 Black cameras, a Teensy 3.2 Microcontroller, an openLOG SD card data logger, and an Adafruit Ultimate GPS. The microcontroller, data logger, and GPS are part of a low-cost $(<$ U.S. \$1000) and low-weight $(700 \mathrm{~g})$ custom solution to collect synchronous high-frame-rate (30 frames/s), wide-FOV, imagery. The goal of the payload was to develop an inexpensive system that when flown along multiple kilometers of coastline could acquire the imagery necessary (at least 5-min timeseries at $2 \mathrm{~Hz}$ ) to estimate nearshore bathymetry using the cBathy algorithm [20], simultaneous to 3-D pointcloud data of the subaerial beach. To do this, the payload was designed to generate a wide FOV from multiple synced cameras in order to acquire long-dwell imagery of the nearshore while moving along the coast. The multiple camera approach enables an improved ground sample distance (GSD) at a lower cost than a single camera with a single fish-eye lens at comparable resolution. In addition, GoPro cameras were selected due to their low-weight, low-cost, low-power requirements, ruggedness of the cameras, and because of their ability to collect high-frame-rate (30-frames/s video) video imagery. Disadvantages to the GoPro cameras include a CMOS rolling shutter which introduces nonlinear image distortion [36], high lens distortion, and no well documented method for triggered time synchronization. To time sync the GoPro video, the microcontroller records and directs two signals (GPS pulseper-second (PPS) and a binary counter) to the two audio channels (left and right) of each GoPro via the mini-USB port. The recorded GoPro audio, automatically synced with the video, is used to synchronize the imagery between cameras and GPS time (delivered as an NMEA string from the GPS, recorded by the microcontroller) in postprocessing.

Each GoPro recorded in $4 \mathrm{~K}$ video mode with an acquisition frame rate of 30 frames/s. The four GoPros are oriented outward facing the bow, stern, undercarriage, and starboard 
(a)

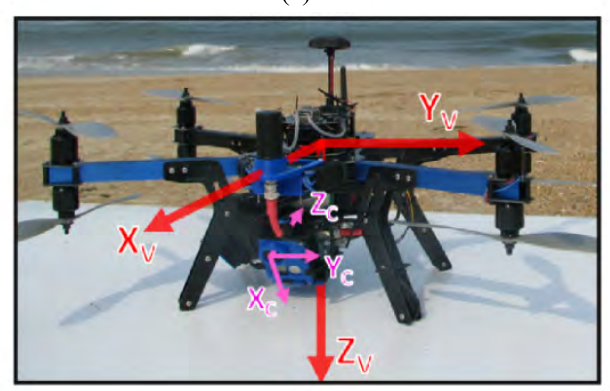

(b)

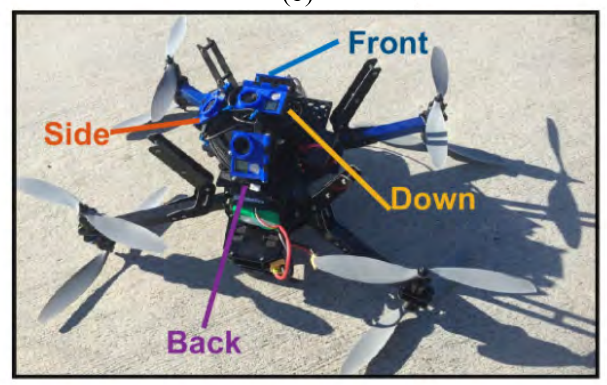

(c)
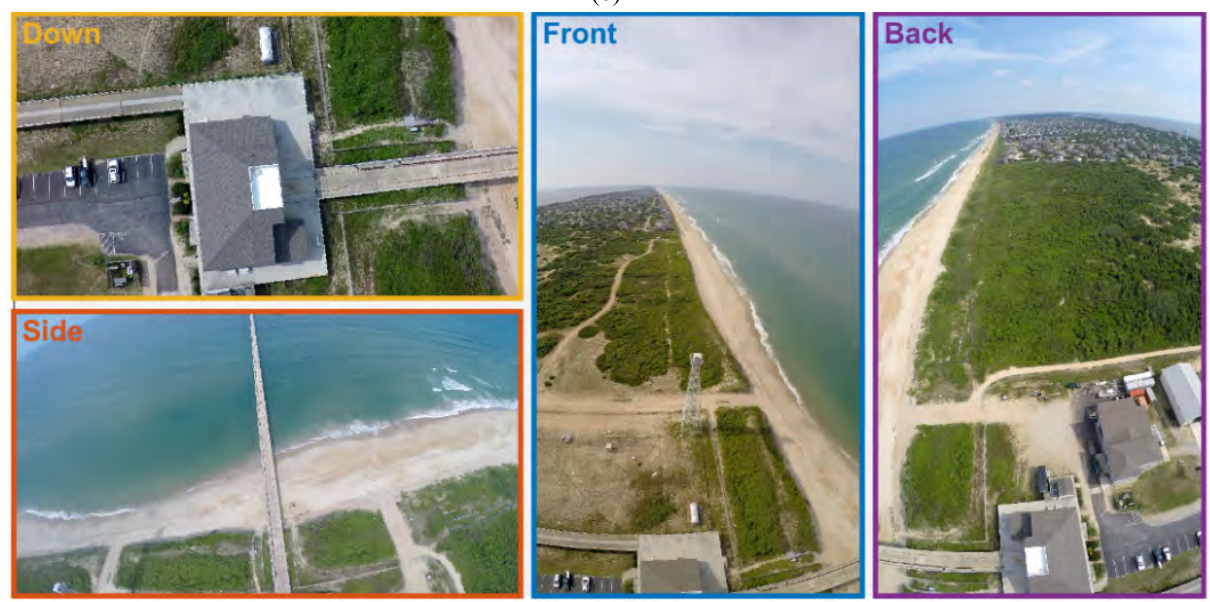

(d)

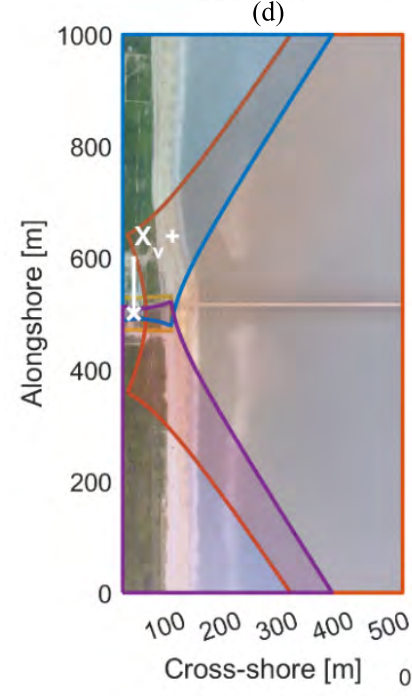

(e)

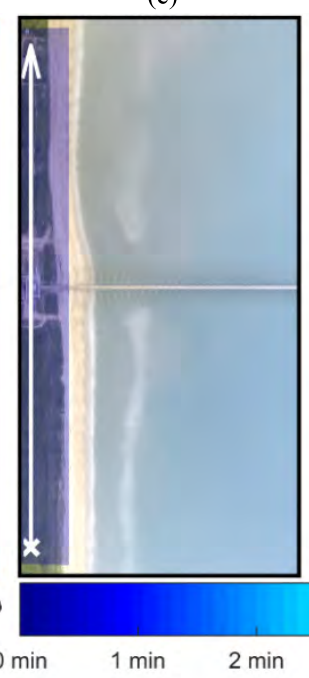

(f)

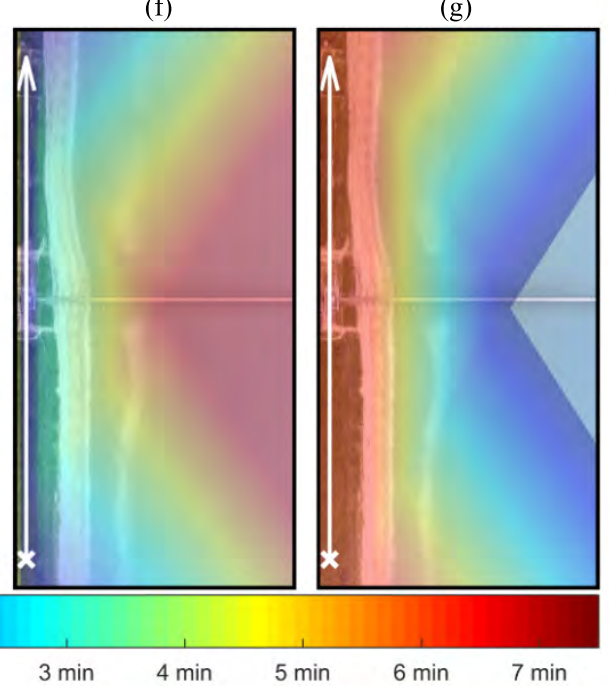

Fig. 1. FOV and dwell time for multicamera payload. (a) Oblique view of UAS with vehicle (red XYZ $\mathrm{Z}_{\mathrm{V}}$ ) and camera (pink XYZ $\mathrm{C}_{\mathrm{C}}$ ) coordinate systems. Camera coordinate system diagramed on Front camera. (b) Undercarraige view of UAS with labeled cameras. (c) Example imagery of UAS cameras. (d) Idealized instantaneous FOV for each camera (colored outlines match B/C label/edge colors) and (e) $-(\mathrm{g})$ total dwell time (min, colorbar at bottom) for each camera. UAS position/trajectory indicated by white X and arrow. UAS platform is assumed level at an elevation of $100 \mathrm{~m}$ and speed of $2 \mathrm{~m} / \mathrm{s}$. Underlying georefereced image is from time-averaged UAS imagery at FRF, Duck, NC, USA.

sides of the X8+ platform and are labeled front, back, down, and side cameras, respectively [Fig. 1(b) and Table I]. The orientation of the four cameras was selected to acquire longdwell imagery of the coast while maintaining land in the FOV to ensure the camera EO could be solved for in the
SfM processing. In addition, nadir imagery was maintained in the center camera to ensure a small GSD and improve the quality of SfM reconstructions. The front, back, and side cameras utilized the standard GoPro fisheye lens with a focal length of $2.97 \mathrm{~mm}$, but the down camera lens was replaced 
with a low-distortion 5.4-mm lens to again improve the quality of SfM reconstruction [37], [38]. At 100-m elevation, oblique imagery for each camera [Fig. 1(c)] combines to cover a theoretical FOV that spans $1 \mathrm{~km}$ in the alongshore and $500 \mathrm{~m}$ in the cross-shore [Fig. 1(d)]. Fig. 1(c) and (d) demonstrates that the front, back, and side cameras provide continuous imagery of the shoreline and offshore waves over the entire area of interest (AOI), whereas the down camera provides high-resolution nadir imagery over the foreshore and dune crest for instants in time for SfM analysis.

Fig. 1(e)-(g) further explores this by highlighting the dwell time of each camera from a single flight at 100-m elevation traversing alongshore at $2.25 \mathrm{~m} / \mathrm{s}$, which was a typical flight plan conducted in the field. Dwell time refers to the total amount of time an area of the study area is in the FOV and recorded by a camera in flight. Due to the small FOV, the down camera provides very short dwell time $(<30 \mathrm{~s})$ of the beach topography [Fig. 1(e)]. This is acceptable since SfM processing relies on acquiring imagery of the topography from multiple viewing angles, rather than dwell time. In addition, topography is not expected to change over the timescale of a flight $(10 \mathrm{~min})$. Fig. 1(f) shows the significant dwell time ( $>6 \mathrm{~min}$ ) offshore provided by the side camera which is suitable for optical analysis of surf-zone waves (e.g., time averaged surf-zone orthophotos or bathymetry). However, a significant portion of the shoreline at the upper and lower reaches of the study area have significantly less dwell $(<3 \mathrm{~min})$. Dwell is increased for these areas with the addition of the front and back cameras to allow for optical analysis of the complete study area shoreline [Fig. 1(g)]. Combined, all four cameras theoretically provide dwell uniformly over the AOI.

In Fig. 1(d)-(g), the study area is approximately equal to the combined FOV of the four cameras at $100-\mathrm{m}$ elevation. However, it is important to note the study area can be extended alongshore and is only limited to platform battery life. For an extended study area at the same vehicle speed and height, all areas will have the same dwell time $(\sim 7 \mathrm{~min})$; however, not all areas will be captured simultaneously and will have to be processed in subsets with lengths of the FOV. Section III outlines the processing workflow for one subset.

\section{DATA Processing}

The processing workflow to transform the raw imagery and timestamp data into coastal data products is outlined in Fig. 2. Complete data processing takes $86 \mathrm{~h}$ (on a computer with 256-GB RAM, a 12 Core Intel Xeon $2.7-\mathrm{GHz}$ Processor, 2 AMD Radeon R9200 GPUs, and an NVIDIA QuadroK600 GPU) for a 1-km stretch of coastline. Each step is detailed in Sections III-A-III-E, and data product depicted.

\section{A. Video Synchronization + Image Extraction (Step 1)}

To obtain synchronized imagery between all cameras in GPS time, video from each camera is extracted and referenced to the binary counter and PPS audio signal input, which in turn is referenced to the NMEA string, binary counter, and PPS signal recorded by the microcontroller log. The resultant product from Step 1 is a set of jpg images from each camera, all synchronized to a single GPS timestamp and geospatial position at $2 \mathrm{~Hz}$. (The physical offset of each camera is less than the accuracy of the GPS, so a single position value is utilized.) By this method, the largest observed discrepancy between cameras for a given timestamp is approximately $16 \mathrm{~ms}$ or half a frame length $(1 / 30 \mathrm{~s})$.

\section{B. SfM Processing (Steps 2-4)}

The full data set of imagery is then processed using Agisoft Photoscan version 1.4.1 to generate the camera pose estimates for each image (Step 2). For initial camera alignment, Photoscan accuracy was set to Highest accuracy with a key point limit of 40000 and tie point limit to 4000 . Adaptive camera model fitting was disabled and camera IOs were not prescribed except for the camera distortion model (Table I). No masks were applied to the imagery. Each image is seeded with camera EOs (position only) provided by the Ultimate GPS with an estimated accuracy of $10 \mathrm{~m}$. After each of the cameras were aligned, a user manually clicks the GCPs in each image and adjusts them to within an estimated two pixels for each camera (Step 3). Once GCP coordinates are assigned and entered, the Photoscan "optimization" is performed, which adjusts the IO and EO for each camera position (Step 4). The computed camera EOs and IOs are then exported for further processing.

The SfM processing is the most computationally expensive part of the workflow ( $80 \%$ of total time, $70 \mathrm{~h}$ ), although it can be significantly reduced with the utilization of high-end GNSS-INS data for the camera EO seed (see the Appendix). The long processing times are due to the selected highaccuracy settings in Photoscan as well as the number of photos utilized. The workflow utilizes more photos than traditionally used for SfM pointcloud generation, four cameras with $98 \%$ overlap versus one camera with $20 \%-30 \%$ overlap. This is because four cameras are required for the large dwell/FOV and $2-\mathrm{Hz}$ imagery is necessary for bathymetry estimates. Camera EO is required for each image for orthophoto generation and thus included even though not necessary for digital surface model (DSM) generation.

\section{Topographic DSM Generation (Step 5)}

Following the trajectory determination, a dense topographic point cloud is then generated using Photoscan's MVS algorithm with depth filtering set to Aggressive and quality Ultrahigh. The point cloud is exported for filtering in the QT Modeler Program version 8.0.7.2. The dense pointcloud is first filtered by removing points below the average tide elevation during the flight. A user then manually removes noise near the shoreline, which results from time-varying texture in the active swash zone. The point cloud, with on average 110 points $/ \mathrm{m}^{2}$, is used to create a topographic DSM in a local rotated coordinate system with $1-\mathrm{m}$ resolution in both the alongshore and cross-shore directions using a triangulationbased linear interpolation in MATLAB. The resultant DSM from Step 5 can be used for exaction of beach topographic products and orthophoto generation. Higher resolution DSMs are available via different interpolation schemes; however, the selected method was adequate for coastline spatial scales of interest $(\mathrm{km})$. 


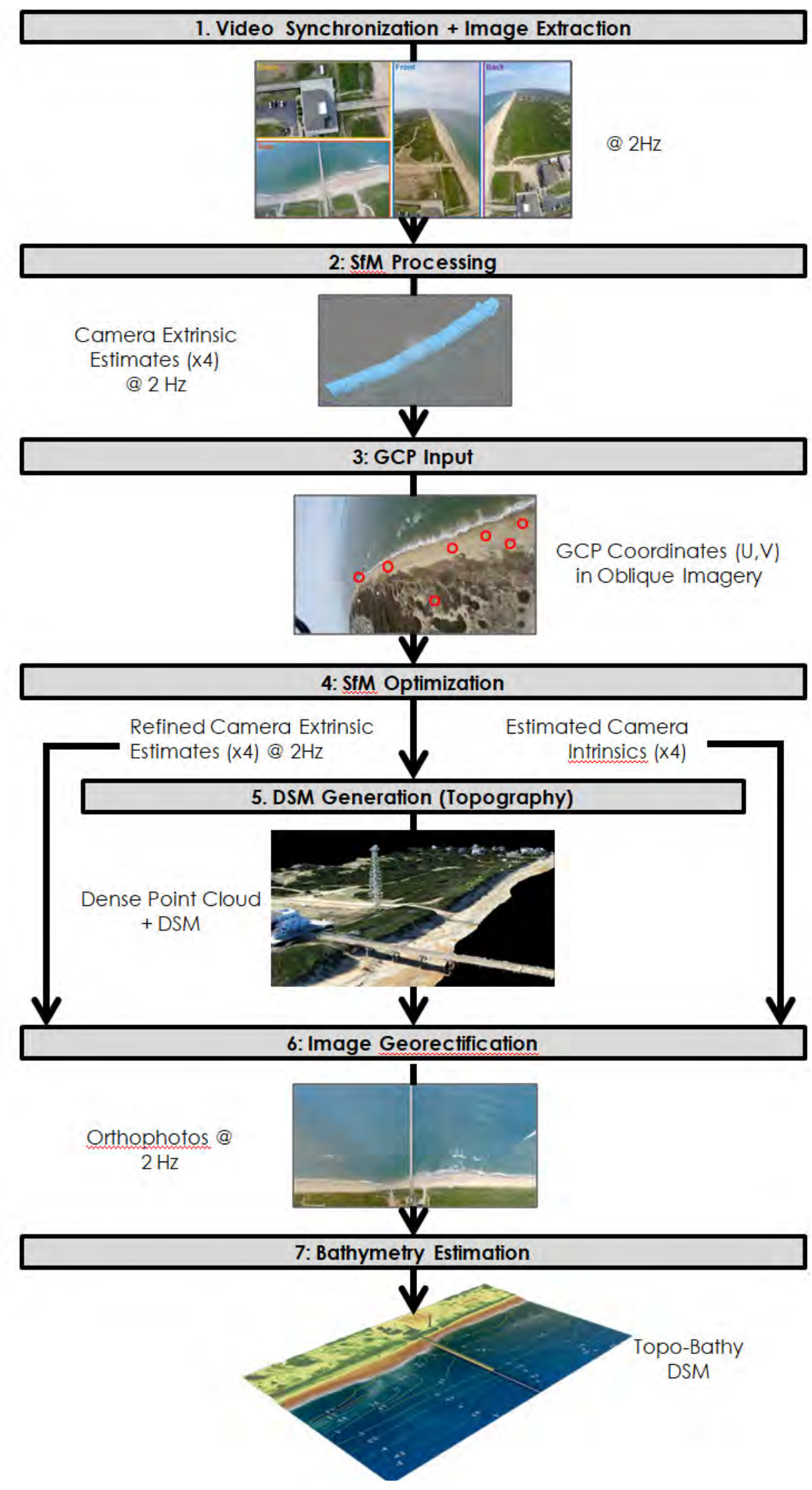

Fig. 2. Processing workflow to produce georeferenced topo/bathymetric DSMs from multicamera payload.

\section{Image Georectification (Step 6)}

A full DSM which contains the water surface and the beach topography is produced for orthophoto generation. The water surface elevation is estimated as the nominal tidal elevation during flight, derived from nearby NOAA tidal station measurements. For each timestep, an orthophoto is generated in MATLAB, using the computed DSM and the estimated camera EOs and IO from Photoscan. DSM coordinates are transformed 
from world to camera coordinates utilizing the estimated EO of the camera for each image. Images are undistorted per the distortion model specified [38], [39]; pixel RGB values are then assigned to each DSM point specified by its location in camera coordinates (Table I). An orthophoto with the same dimensions of the DSM is created from the extracted pixel intensities with each DSM grid cell corresponding to 1 square meter. Grid cell size is dependent on the degree of resolution desired for topographic (dune width) and hydrodynamic (shoreline position, wave breaking) features in the orthophoto. Of particular, importance is the offshore regions; bathymetry inversion algorithms suggest a resolution of at least five pixels per observed wavelength [20]. One pixel/m resolution is well above the required resolution for common gravity waves in 1 to $10 \mathrm{~m}$ depths. However, it is important to note that orthophoto resolution is ultimately limited by the GSD of each image, dictated by camera IO/EOs which should be considered in flight planning (discussed further in Section VI). Orthophotos of the four cameras are merged and saved as a .png file; for areas of camera overlap, the average of the pixel intensities is utilized. These orthophotos make up a $2-\mathrm{Hz}$ timeseries which is used to quantify surf-zone morphology.

\section{E. Bathymetric Estimation + Combined DSM (Step 7)}

The cBathy algorithm [20] utilizes the orthophoto timeseries to estimate bathymetry. Before cBathy processing, the orthophotos are preprocessed. Images are first converted to grayscale and contrast is enhanced utilizing contrast limited adaptive histogram equalization (CLAHE) [40]. The CLAHE algorithm was applied to subset tiles of the image (62 cross-shore by 125 -m alongshore) so onshore wave breaking would not alter offshore contrast. Empty pixel values (areas where dwell is interrupted by nonoverlapping camera seams) are replaced with the time-averaged pixel intensity for that pixel. The entire domain at $1-\mathrm{m}$ resolution, not subsampled, is then processed using the pertinent cBathy settings listed in Section IV for each field site; settings not listed were set to the standard cBathy parameters [20]. Bathymetry estimates were treated as single independent measurements; previous bathymetry measurements were not considered and the cBathy Kalman filter feature was not utilized.

The bathymetry is then filtered; points with a depth error, estimated by cBathy, greater than $1 \mathrm{~m}$ are removed. The bathymetry estimates and topographic DSM points are then treated as individual observations and gridded to the DSM using a triangulation-based linear interpolation as with the topographic DSM to produce a coastal morphologic DSM that can be utilized to estimate coastal parameters such as beach volume and sandbar position. For the two flights presented in this paper, after the application of the $1-\mathrm{m}$ error filter, some of the area near the subaqueaous shoreline was not accounted for $(\sim 10-\mathrm{m}$ cross-shore width). Because there was no overlap between cBathy and SfM results, there was no need to apply a weighting algorithm in the interpolation to give one more credence over the other. This gap or overlap will vary with the quality of cBathy results and wave conditions and improvement of cBathy results near the shoreline may warrant more study.
TABLE II

Environmental Conditions During the Two Flights. Wave Data FOR THE FRF ARE FROM 17-m WATER DEPTH (NDBC STATION 44056) AND Meteorological AND WATER LeVel Data Are FROM THE END OF THE RESEARCH PIER (NOAA STATION 8651370). WAVE DATA For VA BEACH ARE FROM NDBC Station 44064, Meteorological Data Are From NOAA STATION 8638999, AND TIDAL DATA ARE FROM NOAA STATION 8638901

\begin{tabular}{lcc}
\hline \hline & FRF & VA Beach \\
\hline Date & 22 July 2016 & 22 March 2018 \\
Tide Elevation [m, NAVD88] & -0.62 & 0.22 \\
Significant Wave Height [m] & 0.68 & 0.73 \\
Peak Wave Period [s] & 9.09 & 4.76 \\
Mean Wave Period [s] & 4.50 & 4.07 \\
Peak Wave Direction [ ${ }^{\circ}$ TN] & 109 & 38 \\
Wind Speed [m/s] & 5.55 & 3.3 \\
Wind Direction [ ${ }^{\circ}$ TN] & 197 & 3 \\
\hline \hline
\end{tabular}

Wave data for the FRF are from 17-m water depth (NDBC Station 44056) and meteorological and water level data are from the end of the research pier (NOAA Station 8651370). Wave data for VA beach are from NDBC Station 44064, meteorological data are from NOAA Station 8638999, and tidal data is from NOAA Station 8638901.

\section{Data Collection and Control Data}

Two field efforts were conducted to evaluate the methodology discussed above: one near Duck, NC, USA, at the U.S. Army Engineer Research and Development Center's Field Research Facility (FRF) [Fig. 3(a)] on July 22, 2016 and one located at the north end of Virginia Beach, VA, USA, near the Joint Expeditionary Base Fort Story [herein VA Beach, Fig. 3(b)] on March 24, 2018. The FRF flight was flown at an average elevation of 94-m NAVD88 at $8 \mathrm{~km} / \mathrm{h}$ and the VA Beach flight was flown at 97-m NAVD88 at $3.6 \mathrm{~km} / \mathrm{h}$ (slower due to a strong headwind). Both flights were flown autonomously along a predefined route in the NW direction [cyan line, Fig. 3(a) and (b)]. Seven iron cross-style GCPs were used to optimize the SfM trajectory for the FRF site, and nine GCPs were used for VA Beach [magenta circles, Fig. 3(a) and (b), respectively].

Environmental conditions for both survey efforts are shown in Table II; differences between the two sites resulted in slightly different settings within cBathy. The cross- and alongshore domain spacing were set to 5 and $10 \mathrm{~m}$ for the FRF and 10 and $10 \mathrm{~m}$ for the VA Beach sites, respectively. The cross- and alongshore tomographic domain smoothing were 20 and $40 \mathrm{~m}$ for FRF and 20 and $20 \mathrm{~m}$ for VA Beach, respectively. Analysis frequencies for the FRF site were between $1 / 18$ and $1 / 4 \mathrm{~Hz}$ with $1 / 50-\mathrm{Hz}$ resolution. Having shorter period waves, the VA Beach analysis frequencies were focused on higher frequencies, ranging from $1 / 10$ to $1 / 4.5 \mathrm{~Hz}$ with a $1 / 24-\mathrm{Hz}$ resolution.

Significant ground truth data were available at the FRF field site to evaluate the accuracy of the topographic, image, and bathymetric products. To assess the accuracy of subaerial beach topography, UAS-derived topography was compared to terrestrial lidar scans conducted 9 days prior to the flight with no significant erosion/accretion events in between (June 13, 2016). Terrestrial lidar data were collected using a Riegl VZ-2000 scanner from five stationary tripod locations 
(a)

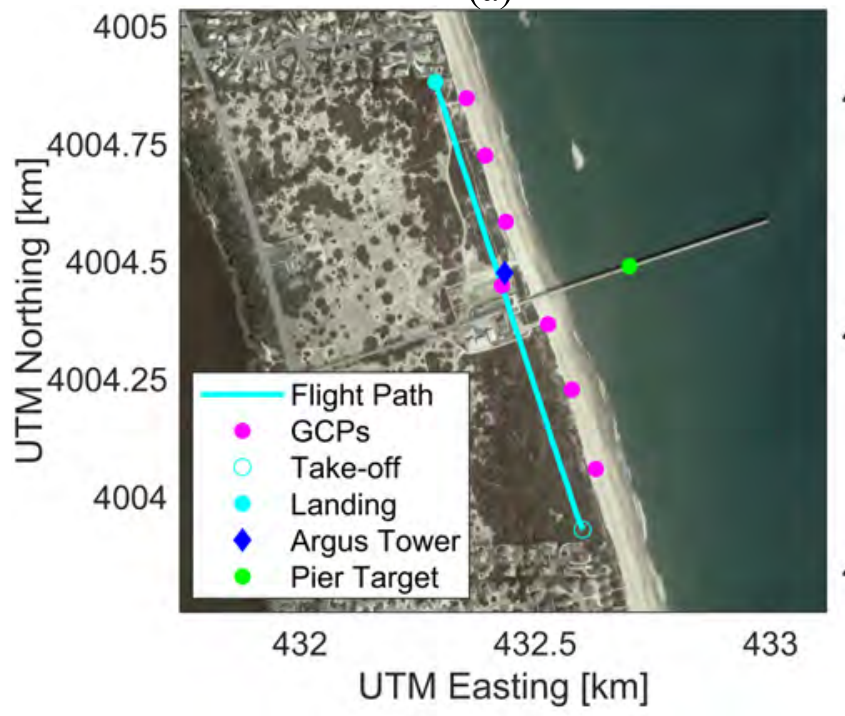

(b)

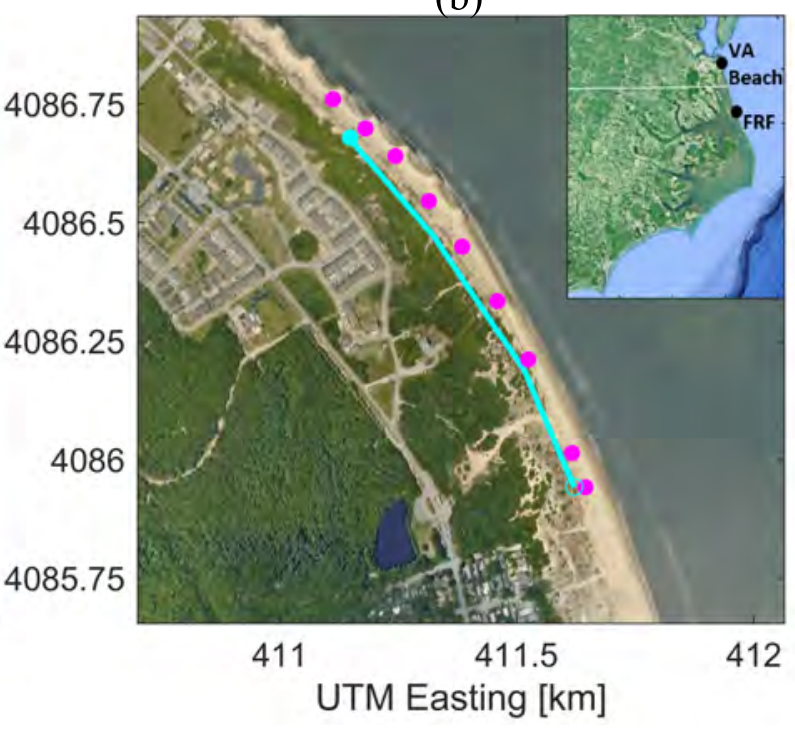

Fig. 3. Aerial imagery of the (a) FRF and (b) VA Beach study sites in UTM Zone 18N. The flight trajectories (cyan) and GCPs used in the SfM processing (magenta circles) for each site are overlain, as well as the location of the Argus imagery tower (blue diamond) and littoral imagery assessment GCP (green circle) for the FRF site.

with theta and phi resolutions of $0.03^{\circ}$. Lidar data were initially rectified using a least-squares fit to the horizontal and vertical positions of five cylindrical reflectors in the FOV, and the six scans were co-registered together following the methodology outlined in [41]. Lidar data were not filtered to remove vegetation, and a DSM was generated with an alongshore and cross-shore resolution of $0.2 \mathrm{~m}$.

Coincident imagery of the nearshore was available from the Argus coastal monitoring station [40, blue diamond, Fig. 3(a)], which provides half-hourly imagery products from six synchronized cameras located at the top of a 43-m fire tower. Imagery from the Argus tower was used to evaluate the rectification of the time-averaged and Brightest orthophotos from the UAS. In addition, an iron cross-GCP on the FRF's research pier [green circle, Fig. 3(a)] was used to assess the accuracy of the orthophoto rectification in the nearshore.

To assess accuracy of UAS-derived cBathy bathymetry, data were compared to the Argus-derived cBathy frequency independent result (Phase 2 [20]) from the same collection time period and also to a vessel-based hydrographic survey conducted on July 26, 2016 (4 days later) using RTK-GPS and an acoustic sensor mounted onboard the FRF's LARC [43]. Since cBathy utilizes alongshore smoothing during the algorithm's fit to the linear dispersion phase maps, control bathymetry data were gridded to match the cBathy analysis points with a smoothing length scale equivalent to the smoothing length scale in the cBathy algorithm to properly evaluate the scale of bathymetric features that cBathy can resolve.

Limited ground truth data were available for the data collected near VA Beach; however, the Joint Expeditionary Base Fort Story provided a bathymetric survey derived from multibeam sonar [collected from a rigid-inflatable-boat (RIB)] well offshore of the surf-zone in a region likely to be relatively stable from May 2017 (exact dates unknown), which was used to coarsely evaluate the offshore bathymetry data from the second flight.

\section{Results}

To assess the accuracy of the system, this section first compares each UAS data product (topography, surf-zone imagery, and bathymetry) to the corresponding ground truth data for the FRF flight (Sections V-A-V-C). Having benchmarked the accuracy of the individual products, Section V-D demonstrates the capabilities of the system at the second field site (VA Beach), and presents an example of the combined topobathymetric surface generated by the system. In addition, limited available ground-control are used to provide an additional validation of the derived bathymetry at the secondary field site in short period waves.

\section{A. FRF Topography}

A 1-m DSM was successfully generated for the entire extent of the study area [Fig. 4(a)] from the dense point cloud (Photoscan reported GCP RMSE of $0.02 \mathrm{~m}$, a measure of optimization fit, not accuracy; Step 5, Fig. 2). To evaluate the ability to use this DSM to map coastal features (e.g., dune and beach morphology), a higher resolution DSM $(0.2 \mathrm{~m})$ was also generated from the UAS point cloud for a subset of the study area [Fig. 4(a)—pink box] and compared to the same resolution DSM from the terrestrial lidar control data [Fig. 4(b)]. Overall, the DSMs compare well, with an RMSE of $0.26 \mathrm{~m}$ and the UAS-derived DSM having a $-0.05-\mathrm{m}$ bias relative to the terrestrial lidar DSM. The largest differences occurred near the dune crest where the UAS DSM was approximately $1 \mathrm{~m}$ below the lidar [blue colors, $\sim 70-\mathrm{m}$ cross-shore, Fig. 4(b)] and on the lower foreshore where the UAS DSM was approximately $0.5 \mathrm{~m}$ higher than the lidar 

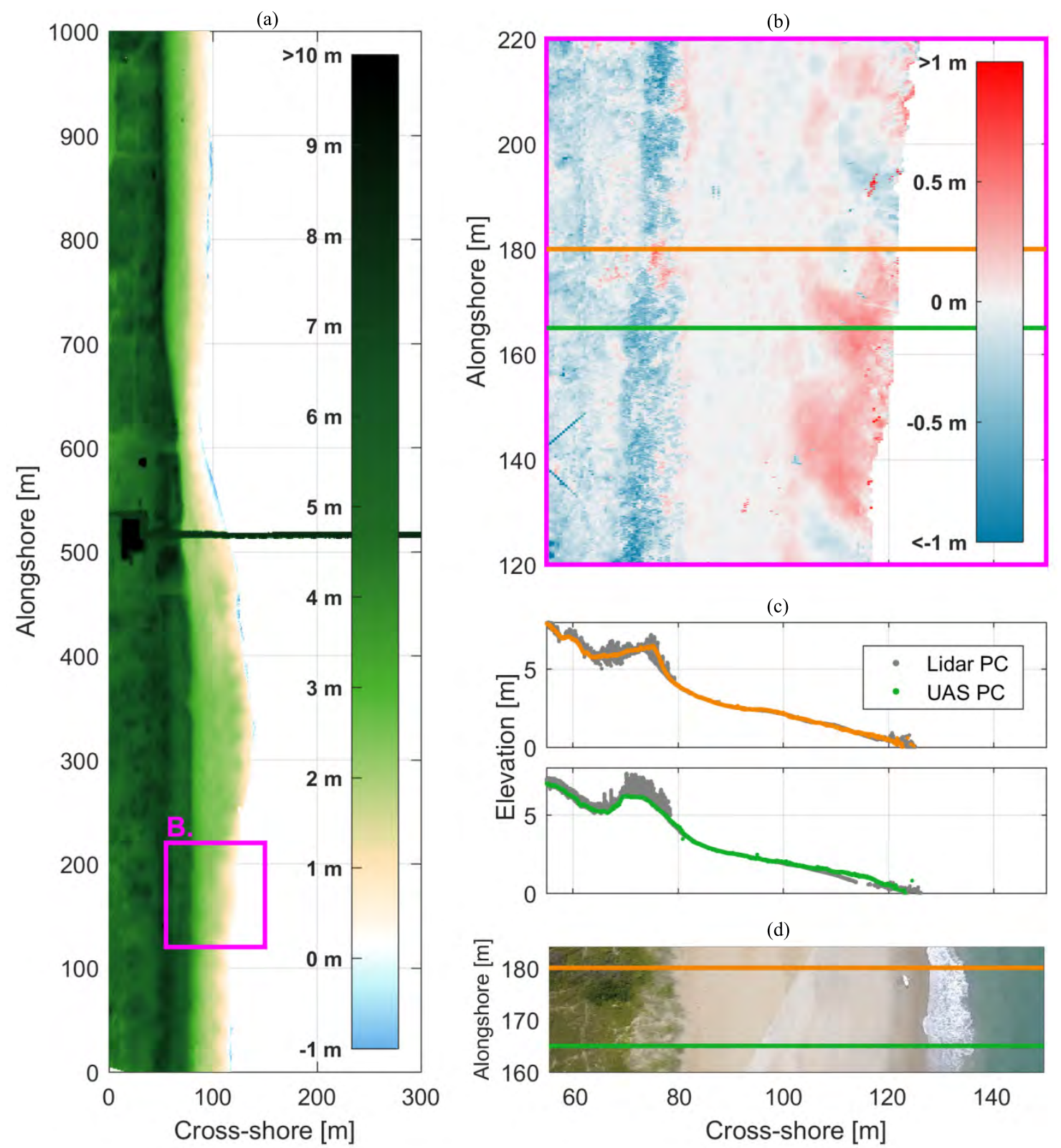

(c)

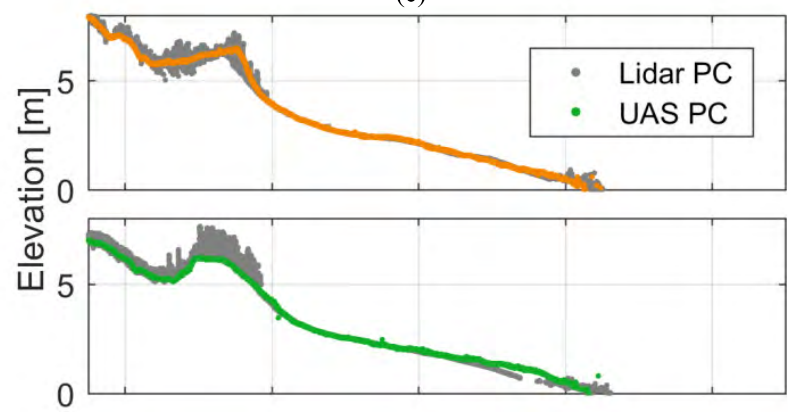

(d)

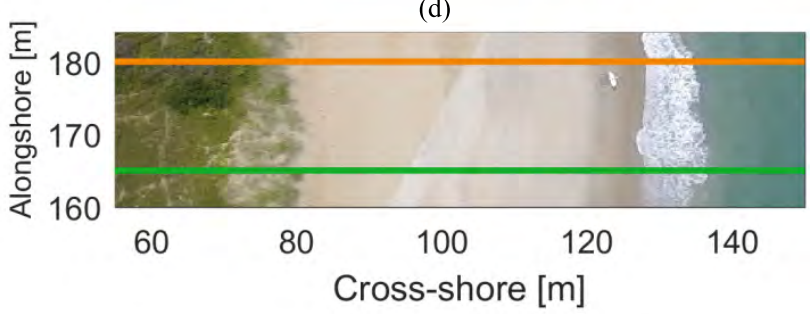

Fig. 4. Topography estimates from July 22, 2016 FRF flight in local coordinate system. (a) DSM created from UAS point cloud (PC) at 1-m resolution. (b) Comparison of UAS DSM and terrestrial Lidar DSM at $0.1-\mathrm{m}$ resolution. Red values indicate UAS DSM has higher elevations, and blue indicates UAS has lower elevations than the Lidar DSM. Colored lines indicate position of cross-shore profiles in (c). (c) PCs of UAS (green, orange) and Lidar (gray) within $0.2 \mathrm{~m}$ of cross-shore profile lines in (b). (d) High-resolution orthophoto over compared profiles. Terrestrial Lidar scan completed on July $13,2016$. Elevations in NAVD88.

DSM ( 110-m cross-shore). The foreshore discrepancies are most likely due to the time differential of the scans and changing morphology of the beach. Areas not expected to change during those timescales (cross shore position 80-100 $\mathrm{m}$ ) have small error $[<0.05 \mathrm{~m}$; light colors, Fig. 4(b)]. There is also a slight overestimation of elevation $(0.25 \mathrm{~m})$ on steeply sloped dune faces [Fig. 4(b), alongshore positions 200-220 m].

Examination of the UAS (colors) and Lidar (gray) point clouds along two transects with an alongshore width of $0.2 \mathrm{~m}$ [Fig. 4(c) suggests that elevation discrepancies on the heavily vegetated dune crest are due to how each method perceives and resolves vegetation. For both profiles, the UAS pointcloud has less vertical variance, particularly behind the dune. In regions with sparse vegetation, such as the Sea Oats on the foredune crest [green profile, 70-80-m cross-shore, Fig. 4(c) and (d)], the SfM analysis resolves the true topography, as it cannot resolve the individual stalks. In contrast, the lidar provides returns off of the stalks and the sand surface, but because a DSM was generated (instead of a bare earth digital elevation model), the large offsets in this region in the DSM comparison [Fig. 4(b)] reflect the height of this vegetation. In regions of denser vegetation [orange profile, cross-shore 65-75, Fig. 4(c) and (d)], the ground is more obscured in the imagery, and the SfM analysis utilizes tie points within the vegetation, 
(a)

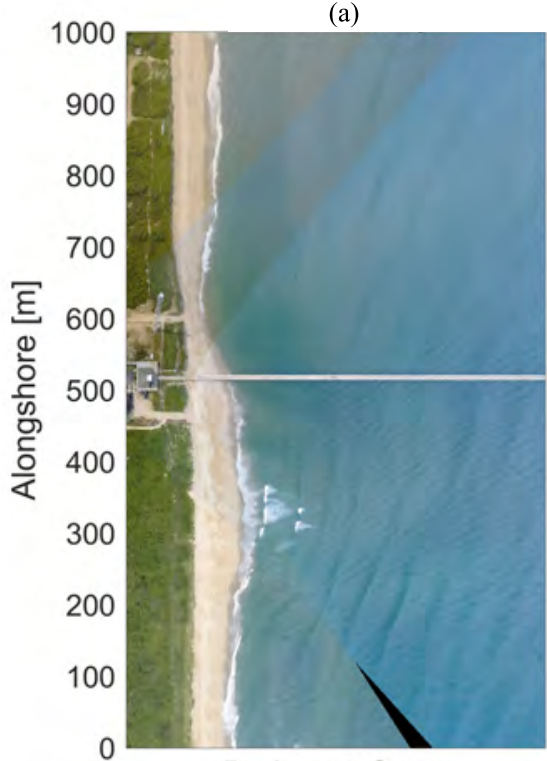

(d)

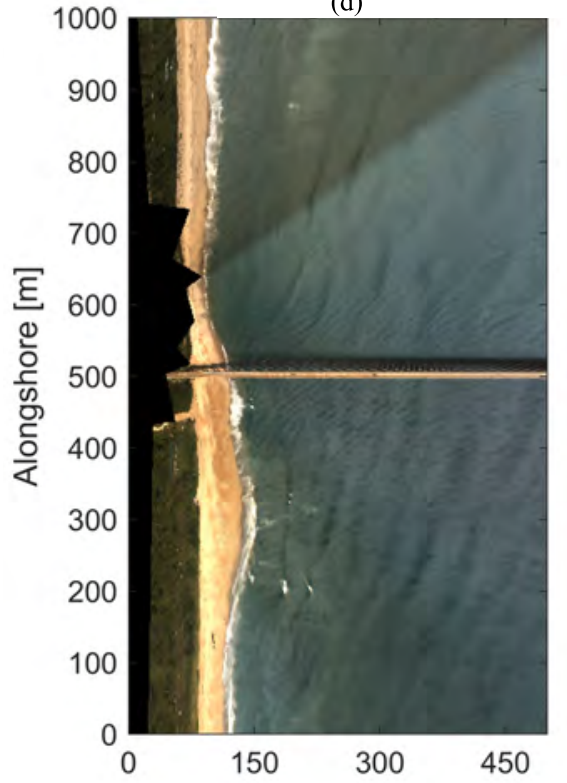

(b)

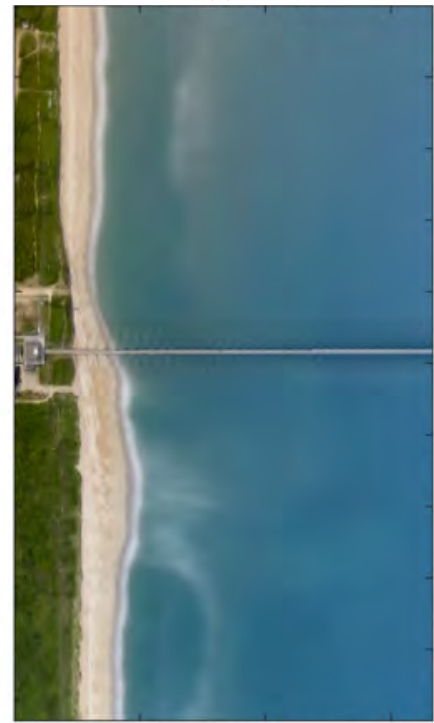

(e)

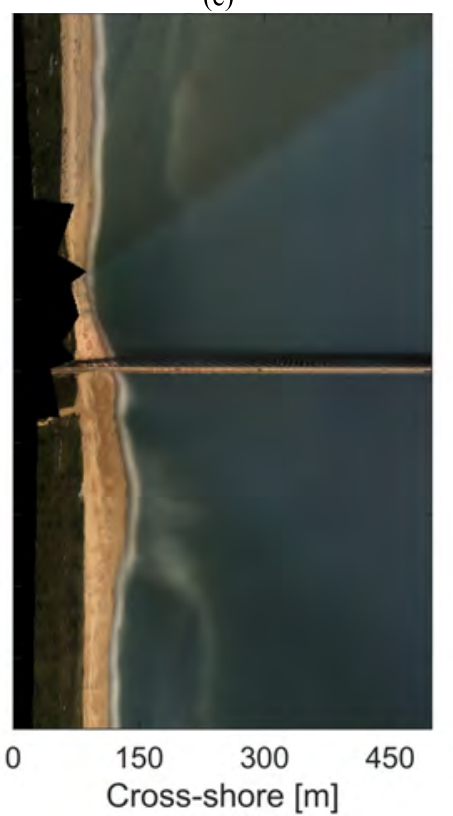

(c)

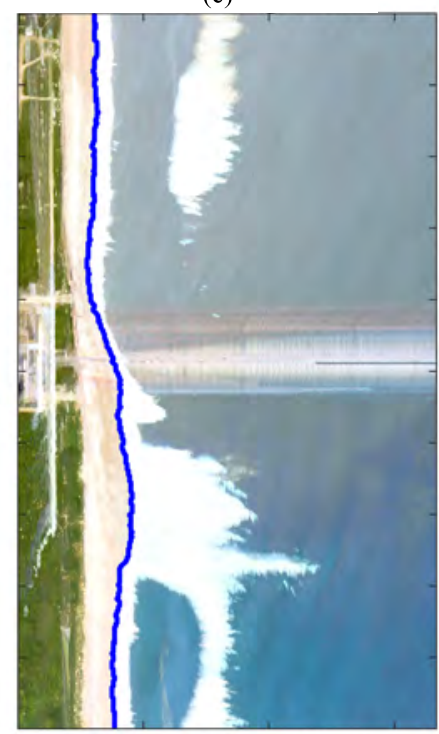

(f)

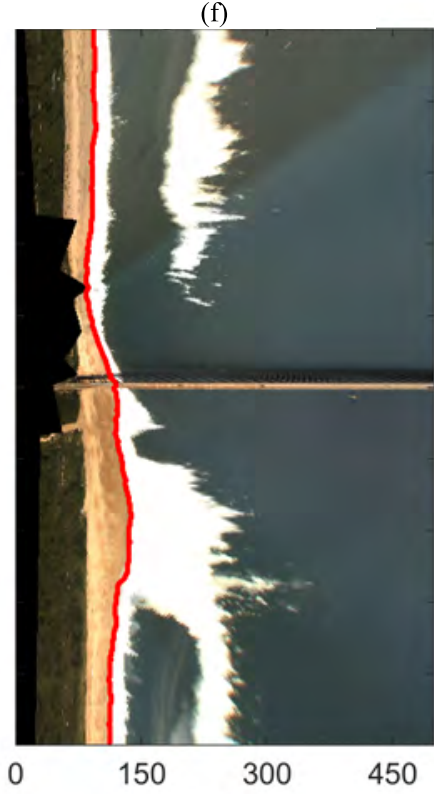

Fig. 5. Merged and rectified orthophotos in FRF local coordinates of a (a) and (d) single frame (not time-matched), (b) and (e) time-averaged, and (c) and (f) Brightest image from the UAS and the Argus tower, respectively, at the FRF field site. In (c) and (f), the cross-shore position of maximum runup is overlain in blue and red, respectively.

providing topographic elevations that are somewhere between the bare-earth and the top of the vegetation.

\section{B. FRF Surf-Zone Imagery}

Qualitatively, single-frame, time-averaged (Timex), and Brightest orthomosaics of the surf zone from the FRF flight compare well to imagery from the FRF Argus data during the collection (Fig. 5). Wave crests are visible across similar portions of the merged single-frame imagery [Fig. 5(a) and (d)] and indicate comparable refraction patterns in the lowfrequency swell. (Note that the Argus single frame is not exactly coincident in time to the UAS single frame.) In addition, a higher frequency wind-wave out of the SE is visible in both the UAS and Argus images in the bottom right portion of the merged images, where the camera pose is aligned closer to the wind-wave propagation direction [Fig. 5(a) and (d)]. Wave breaking patterns in the time-averaged [Fig. 5(b) and (e)] and Brightest images [Fig. 5(c) and (f)] from the UAS and Argus tower also agree well, with both indicating wave breaking (white regions) over a shore-attached sandbar on the south property and over a shore-parallel bar north of $600-\mathrm{m}$ alongshore. In addition, foam that is advecting with the alongshore current is visible in the shore-parallel trough south of 200-m alongshore in both the UAS and Argus imagery. Due to the changing oblique views as the UAS transits along the property, projection errors near the pier (which stands $7.6 \mathrm{~m}$ off the 
(a)

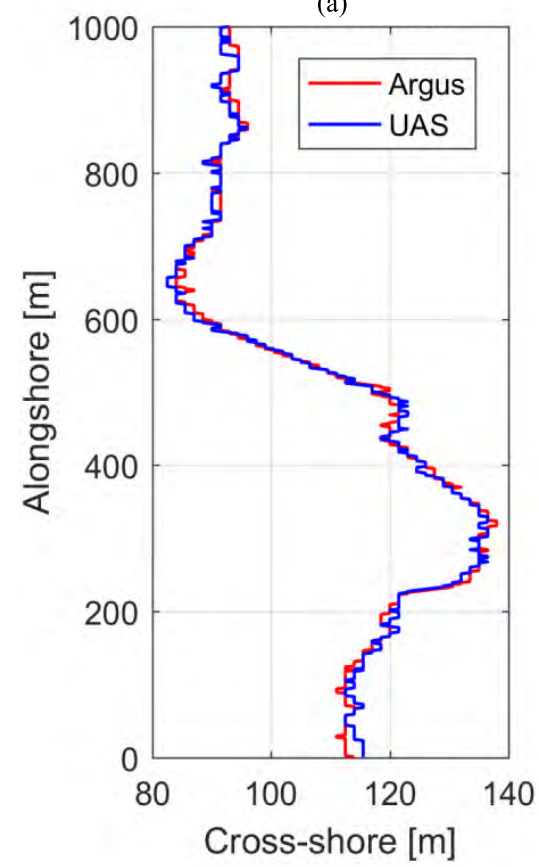

(b)

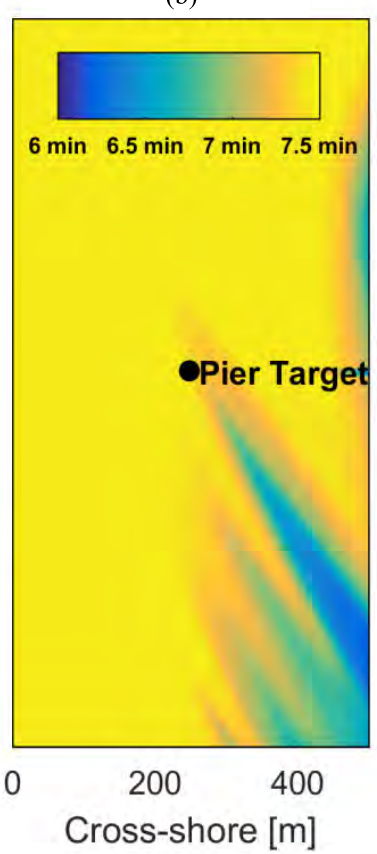

(c)

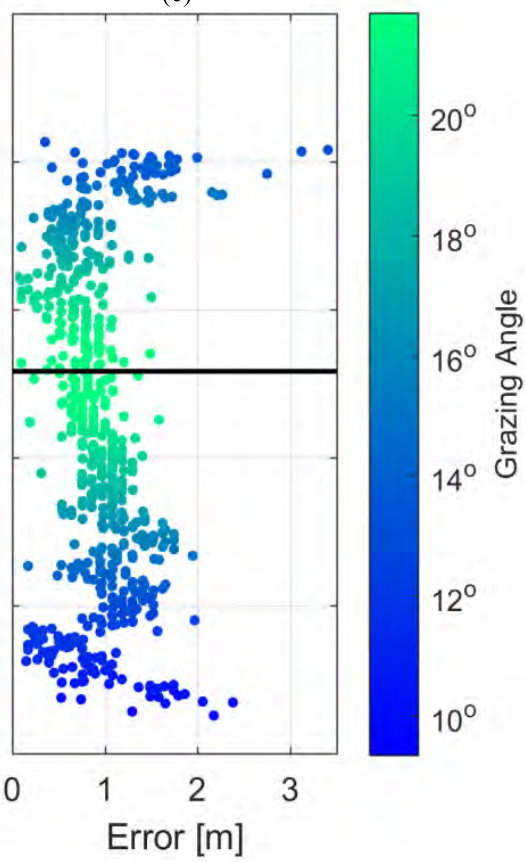

Fig. 6. Orthophoto accuracy at FRF site. (a) Maximum runup position estimates derived from UAS (blue) and Argus (red) Brightest orthophotos [c) and (f)]. (b) Total dwell time across domain. (c) Horizontal error of pier target position in each orthophoto. Y-axis represents alongshore coordinate of UAS at image capture. Color indicates relative grazing angle of UAS and target. Black line is the alongshore pier target coordinate.

water surface) are visible in the UAS Brightest imagery [Fig. 5(c)].

The time-dependent surf-zone orthophoto products (e.g., Timex and Brightest) developed for Argus are commonly used to quantify beach and surf-zone morphological features (e.g., shoreline and sandbar position [16], [43], [44]). To evaluate any differences in surf-zone morphological features, we compared the position of the maximum runup interface from the UAS and Argus Brightest images [blue and red lines, Figs. 5(c) and (f) and 6(a)]. To extract the maximum runup interface, a Scharr kernel was convolved with the Brightest image in order to highlight dark to light edges. A cost-function was then used to connect the identified edges across the image within a user-defined region centered on the shoreline. For each alongshore location, a Gaussian curve was then fit to each cross-shore transect of the convolved image, using the cross-shore location identified in the cost function as the initial center of the Gaussian curve, to identify the cross-shore location of the runup edge. The root-mean-squared difference (RMSD) between the Argus and UAS imagery in the cross-shore position of the maximum runup along the length of the property was $1.36 \mathrm{~m}$ with a slight offshore bias to the UAS runup line of $0.12 \mathrm{~m}$. Differences between the two runup edges could be due to differences in dwell $\sim 7 \mathrm{~min}$ versus $10 \mathrm{~min}$ ) or slight rectification errors in either product.

In addition, to evaluate the quality of the time-dependent UAS-derived surf-zone orthophotos offshore, spatial variations in dwell of the UAS imagery were calculated [Fig. 6(b)] and orthophoto rectification accuracy was quantified throughout the flight using an independent GCP on the FRF pier deck [Fig. 6(c)]. Differences between actual dwell [Fig. 6(b)] and idealized dwell [Fig. 1(e)-(g)] are a result of the actual UAS trajectory varying from the ideal trajectory due to wind. Despite this, the majority of the study area has a similar dwell time of $7.5 \mathrm{~min}$. Areas of decreased dwell have data short intermittencies which could affect imagery data products and bathymetry estimates.

To evaluate rectification accuracy offshore, the horizontal rectification error of a GCP target located on the pier 200-m offshore [Figs. 3(a) and 6(b)] was compared to UAS alongshore position during the flight and relative grazing angle between the target and UAS [Fig. 6(c)]. To assess the target, orthophotos of the surrounding area $(20 \mathrm{~m} \times 20 \mathrm{~m})$ were rectified using the constant elevation of the pier deck (7.56-m NAVD88) and the GCP position was manually clicked by a user. Overall, errors are on the order of $1 \mathrm{~m}$, with a slight increase to $3 \mathrm{~m}$ when the UAS was farthest from the target and had the most acute grazing angles [blue colors, Fig. 6(c)]. Most accurate rectification occurs when the UAS is closer to the target and has higher grazing angles to the target, i.e., when the target is along centerline of side camera FOV at a close distance. This is because uncertainty in the camera EO, IO, and DSM elevation propagate to orthophoto error more significantly at farther distances and lower grazing angles. By the same principle, it is expected rectification errors at the water surface may be up to $10 \%$ higher since the water surface is approximately $7 \mathrm{~m}$ lower and farther from the UAS.

\section{FRF Bathymetry}

Bathymetry derived from the UAS using cBathy [Fig. 7(a)] and measured with the LARC [Fig. 7(b)] compared very well [Fig. 7(c), (f), and (g)]. Offshore of the surfzone, the Argus 

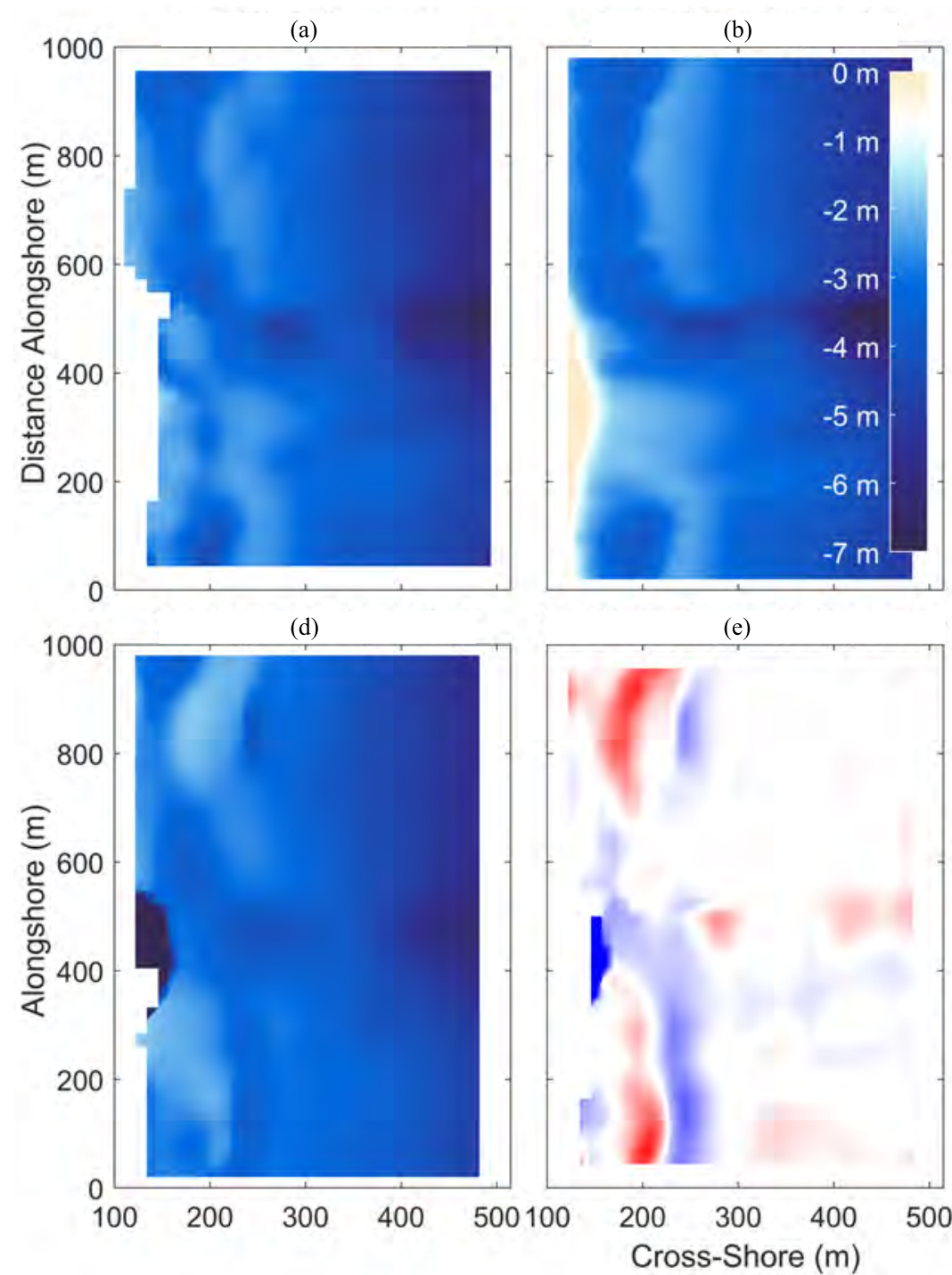

(b)

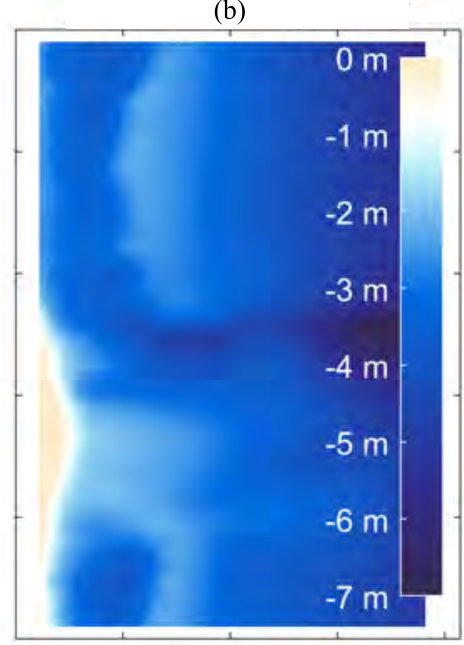

(c)

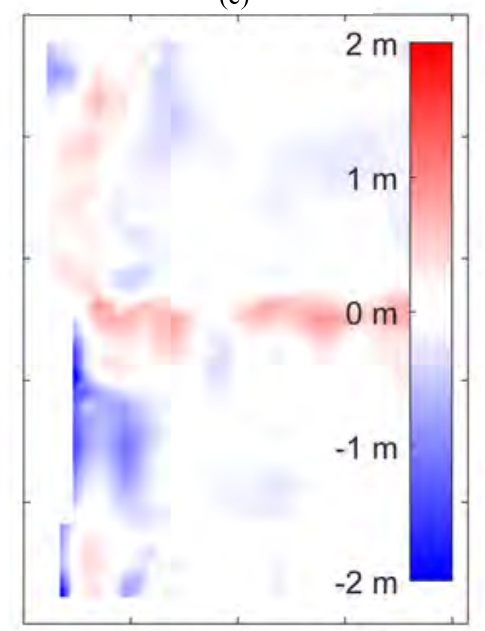

(f)
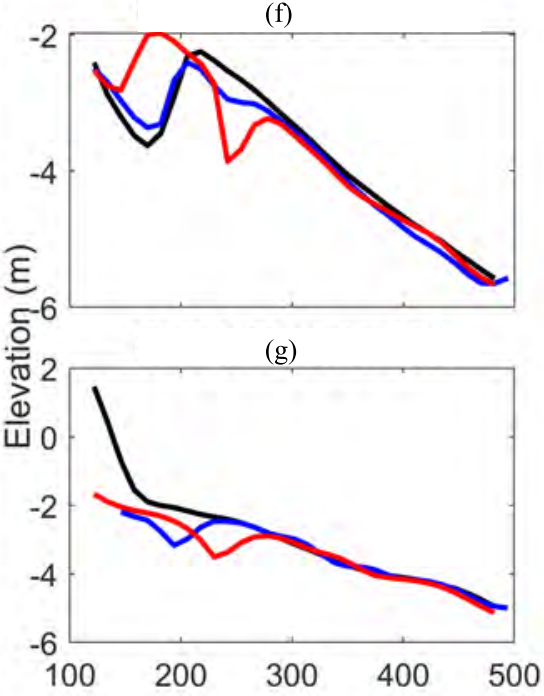

Fig. 7. FRF bathymetry estimates and comparisons in local coordinate system and NAVD88 elevation. (a) UAS derived bathymetry from July 22 , 2016 20:20 flight. (b) Surveyed bathymetry by LARC on July 26, 2016. (c) Difference between UAS and LARC bathymetry. Red indicates UAS underestimates depths and blue indicates UAS overestimates depths compared to the survey. (d) Argus-derived bathymetry from July 22, 2016 20:30 collection. (e) Difference between UAS and LARC bathymetry. (f) and (g) Bathymetric profile comparisons between LARC (black), Argus (red), and UAS (blue).

and UAS-derived bathymetry compared similar to each other and the LARC control bathymetry [Fig. 7(d)-(g)]. Near the sandbar, the UAS bathymetry accurately resolved the sandbar morphology and appeared to have fewer artifacts due to wave breaking when compared to the Argus bathymetry near the sandbar [compare red and blue lines to the black line, Fig. 7(f) and (g)], perhaps due to less wave-breaking during the 7-min UAS flight versus the 20-min Argus collection. RMSE and bias for the UAS bathymetry relative to the LARC were 0.34 and $-0.05 \mathrm{~m}$, respectively, whereas RMSE and bias for the Argus bathymetry relative to the LARC were 0.57 and $-0.03 \mathrm{~m}$. The largest differences between the UASderived bathymetry and the LARC control bathymetry [dark blue and red colors, Fig. 7(c)] occurred in the center of the domain near the FRF pier ( 516-m alongshore), where the pier likely interfered with the observations of waves, and also near the shoreline, consistent with prior work [18], [43].

\section{Additional Study Site: VA Beach}

The multicamera UAS system was also tested at the VA Beach field site, and the system provided a comparable suite of data products, including orthophotos [Fig. 8(a)(c)], a dense point cloud with an GCP RMSE of $0.01 \mathrm{~m}$ (Photoscan reported - a measure of optimization fit and not of the accuracy of the point cloud), and a seamless topobathymetric surface [Fig. 8(d)]. The offshore FOV of the side camera appears smaller in the snapshot image [Fig. 8(a)] than when compared with the FRF imagery [Fig. 5(a)] due to high wind-speeds approaching from the port side of the UAS which affected the platform's orientation (roll). However, as can be seen in the time-dependent Timex and Brightest imagery [Fig. 8(b) and (c)], the front and back cameras filled in data in these offshore regions during some portions of the flight. The shoreline, breakwater structures ( $>900-\mathrm{m}$ alongshore), and wave breaking regions over the sandbar were well 
(a)

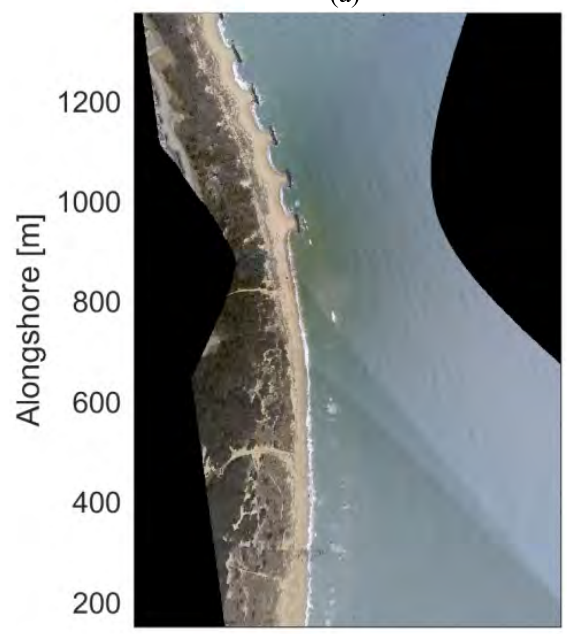

(d)
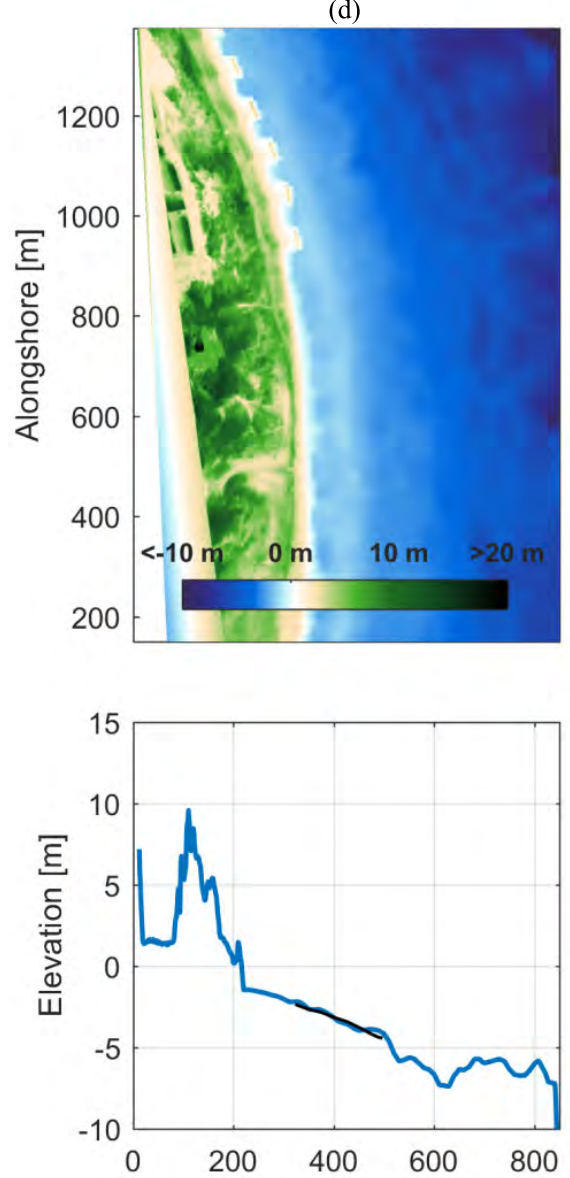

(b)

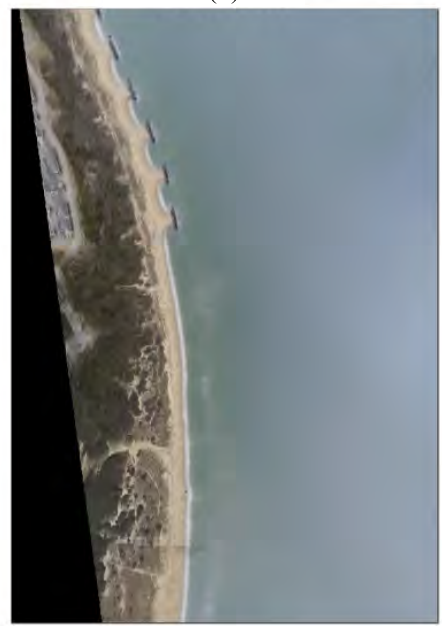

(e)

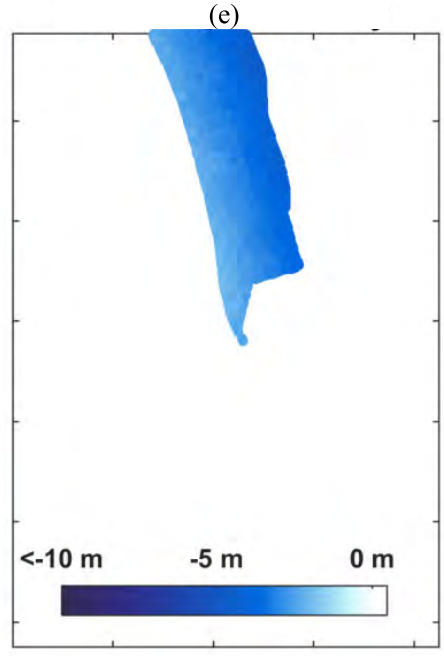

(g)

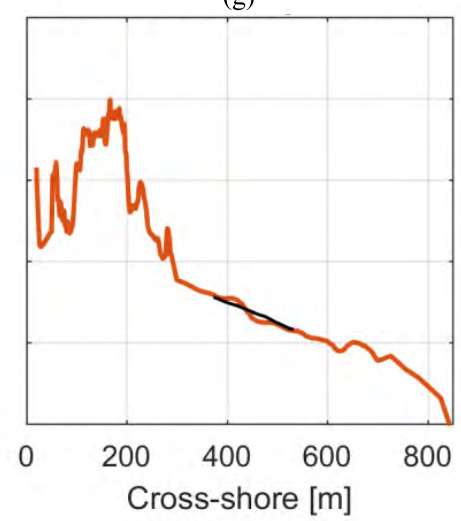

(c)

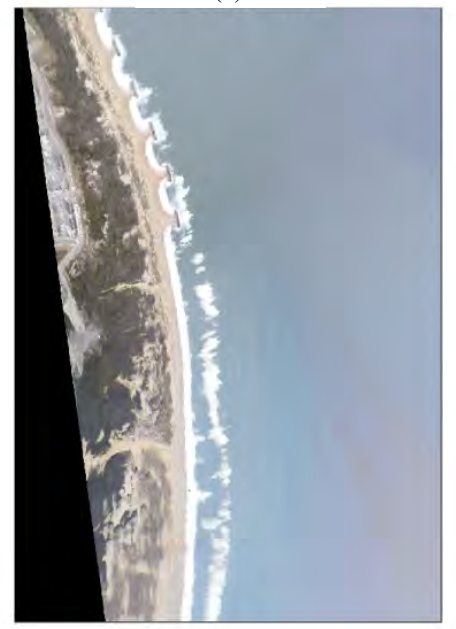

(f)
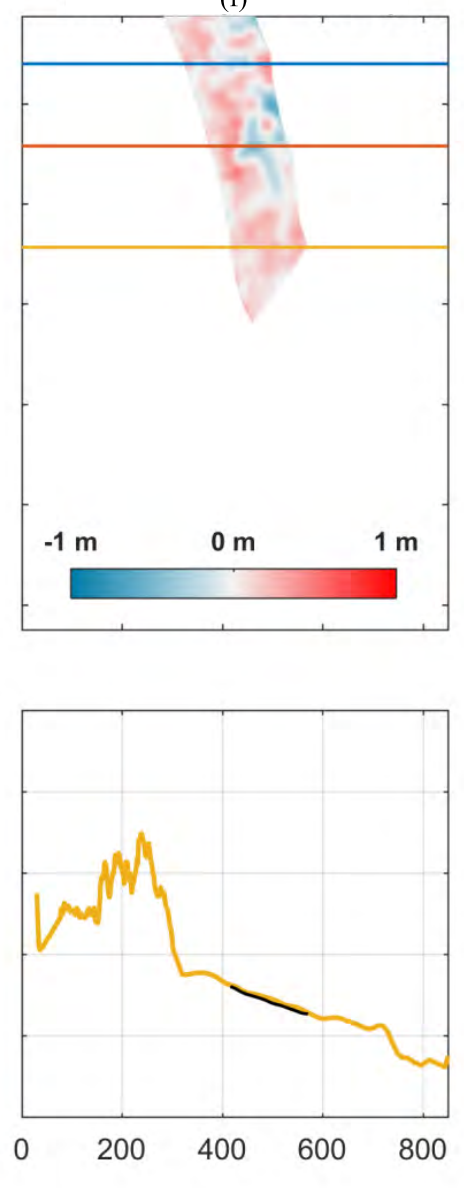

Fig. 8. Results from VA Beach flight in local coordinates and NAVD88 elevation. Georectified imagery: (a) example snapshot; (b) time-averaged; and (c) Brightest. (d) Combined DSM from UAS flight on March 24, 2018 at $1 \mathrm{~m}$. (e) Surveyed bathymetry from 2017. (f) Comparison of UAS DSM and 2017 DSM. Red values indicate UAS DSM has higher elevations, and blue indicates UAS has lower elevations than the 2017 DSM. (g) Cross-shore elevation profiles of UAS (colored) and measured 2017 bathymetry (black).

resolved in the time-dependent Timex and Brightest imagery [Fig. 8(b) and (c)], suggesting high-quality rectification of the long-dwell imagery throughout the flight.

Multibeam sonar bathymetry data were available for a portion of the study site [colors, Fig. 8(e)], and the multibeam bathymetric data compare well with the UAS-derived bathymetry data [Fig. 8(f)]. Differences in the elevations of the overlapping region [Fig. 8(f)] are quite small, with an overall RMSE of $0.17 \mathrm{~m}$ and bias of $0.06 \mathrm{~m}$. Depth mismatches appear to vary spatially [Fig. 8(f)] with cBathy producing 
a more irregular surface than the multibeam data; however, the overall magnitude of the depths and slopes are correct, as can be seen in example transect comparisons [Fig. 8(g)]. Overall, the VA Beach data set demonstrates the multicamera system's applicability at other field sites and in shorter-period waves (Table II).

\section{DISCUSSION}

\section{A. Sources of Error}

As presented above, coastal topography and bathymetry was successfully generated from the multicamera imagery at two field sites: FRF and VA Beach. While overall the low-cost system provided good estimates of topography and bathymetry at both sites, it is important to consider potential sources of error in different data products, which in some cases may be dependent upon environmental conditions (e.g., amount of wave breaking for bathymetry products; lighting for topographic products) or the environment characteristics themselves (e.g., sediment characteristics or land cover that may affect the quality of the topography products). In addition, in Section V, all of the presented results used methodology which required known GCPs to improve the camera EO. Utilizing GCPs can be a time-consuming process, both to survey in the field and to utilize in postprocessing. Techniques to remove the reliance on GCPs for this multicamera system (through the integration of a high-end GPS-INS system: Applanix APX-15) are explored in the Appendix, and additional error metrics are quantified there.

1) Topography: Significant work in the literature has explored the spatial accuracy of topographic point-clouds and DSMs produced by SfM and MVS algorithms, and the sources of the observed errors [37], [47], [48], including in coastal settings [33], [35], [49]. Errors in final products are often observed to be spatially variable (similar to the results of this paper) and can be related to a number of factors including: the distribution of GCPs, spatially variable texture in the scene, image grazing angles, blurry or noisy imagery, or low image overlap. In the case of this paper, the chosen concept of operations (CONOPs) may mediate or exacerbate some of these factors.

For example, our CONOPs require relatively slow flight speeds, oblique look angles, and high frame rates (in order to generate dwell and high-resolution over the moving waves), meaning that image overlap on the beach is rarely a problem (in fact the 2-Hz imagery can be subsampled to provide faster DSM generation). However, the GoPro also utilizes a rolling shutter, which can introduce image blur or lens distortion that is not captured by the Agisoft lens distortion models, particularly in windy conditions when platform vibrations increase. Our flight CONOPs included both nadir and oblique imagery in one flight line, which may have reduced SfM "doming" errors which can result from solving the radial distortion of the imagery simultaneously to the EO parameters [37], [50], [51]. Conversely, our CONOPs also means that all of the matching keypoints result from image overlap, and not sidelap, which can decrease SfM accuracy. In addition, because of the oblique imagery, dense reconstruction occurred well outside of the AOI, and these erroneous regions were removed from the point cloud since they likely had high error due to the viewing geometry [47]. Similarly, the offshore edge of the dense point clouds also contained artifacts which had to be manually removed, which were likely due to the MVS algorithms attempting to reconstruct a surface with moving swash waves. Also, because of the long, linear nature of the coastal sites studied here, time constraints and resources prevented distribution of the control points in the crossshore and alongshore directions, and so topographic point cloud quality may be increased through additional GCPs [37] or through the addition of high-precision GPS onboard the aircraft (see the Appendix).

Finally, it is important to note that some coastal settings may pose unique problems for SfM, since grain size characteristics of sandy beaches can vary spatially on the order of meters (changing image texture within a site) or from site to site, which may influence the quality or number of available tie points. For example, there may be insufficient contrast on homogenous light colored sandy beaches for the SfM and MVS algorithms to reconstruct 3-D pointclouds. However, for the two field sites tested here, this was not a problem.

2) Surf-Zone Imagery: Properly rectified surf-zone imagery is required for accurate wave speed measurements from the cBathy algorithm. Errors in rectification of the surf-zone orthophotos can result from a variety of factors including: 1) poor trajectory estimation by Photoscan; 2) errors in camera synchronization; 3 ) errors in the camera lens distortion model; and/or 4) errors related to an assumed flat water surface. Photoscan may poorly estimate the trajectory if there are: lowquality matches and distribution of matches during keypoint matching, instability in each camera's interior, or errors in GCP positions either during the survey or when manually assigned pixel coordinates. A few milliseconds in poor sync accuracy between cameras on a moving platform will allow a camera to rotate and translate relative to the other cameras, potentially causing incorrect overlap along the seams. Camera sync accuracy was tested by benchtop testing the sensors while each was pointed at a computer screen with a refresh rate of $60 \mathrm{~Hz}$. This test did not show any inaccuracies in synchronization, indicating that the synchronization was better than $17 \mathrm{~ms}$. In addition, errors in the camera distortion model may lead to uncorrected distortion of the image across the domain, resulting in inaccurate photogrammetric calculations. Finally, surf-zone imagery was rectified to a flat water surface at the average tide level for the flight. As wave height increases and grazing angle decreases, projection errors may occur as a result of this methodology which could lead to errors in wavelength or mapping of surf-zone features [52].

Analysis of the quality of the imagery in this example suggest these rectification errors were fairly minimal (Figs. 5 and 6), but the significance of this error on offshore imagery and bathymetry estimates is dependent on the distance from the UAS and the environmental conditions. For example, as shown in Fig. 5, large-scale qualitative features such as the breaker zone are congruent. However, a 1-3-m error was observed on the pier target, roughly $200 \mathrm{~m}$ from the UAS (Fig. 6), which could affect offshore wavelengths, particularly if the error is due to camera elevation/orientation error, 
rather than horizontal displacement, as horizontal orthophoto error is sensitive to elevation and camera orientation. This could increase or decrease measured wave celerities in optical bathymetry algorithms and therefore introduce errors in depths. To what degree this occurs (and would be important) is dependent on both the study area and the wave conditions. Optical signatures of peaks and troughs of longer waves are less susceptible to shifts of 1-3 m than shorter waves. For example, a $3-\mathrm{m}$ error is not expected to cause significant wavelength error for $9.6 \mathrm{~s}$ waves in $3 \mathrm{~m}$ depth for the FRF field site, which would have approximately a 50-m wavelength.

3) Surf-Zone Bathymetry: The accuracy of surf-zone bathymetry may be effected by the rectification of the orthophotos (discussed above), or by inaccurate depth estimates provided by the cBathy algorithm (see [46] for a good review). It is important to note that many published accuracies of the cBathy algorithm are for the Kalman-filtered (runningaveraged) bathymetry results processed on 17-min timeseries, as the algorithm is traditionally run on tower-mounted cameras [20]. The UAS-derived results presented here reflect shorter dwell times and also are the instantaneous frequencycombined results (Phase 2 [20]), as we are unable to average through time over many hours of collection. Therefore, it is vital to select flight windows during favorable environmental conditions which increase the probability of good results. For example, the excellent agreement shown for these two field sites is likely due to the low wave conditions on the days of the collections - at both sites wave breaking over the bar (shown by [46] to introduce large artifacts in depths near the sandbar) was infrequent (e.g., compare Timex and Brightest images in Figs. 5 and 8).

The orthophoto timeseries utilized here are significantly shorter than the standard timeseries used in Argus cBathy processing, and may have intermittent gaps depending on platform orientation during flight [see Figs. 5(a), 6(b), and 8(a)]. As a result, the quality of the cross-spectral analysis used in cBathy may be significantly reduced. However, we found that in these cases 5-7 min of dwell still produced quality results, consistent with prior work [2], [26]. Finally, at both sites, cBathy produced depths that were too deep close to shore (also similar to previous work), which may have affected slopes and sea-bed elevations immediately near the shoreline in the final combined topo-bathymetric surface. The extent of these errors were limited in this paper due to the favorable wave conditions. Limited breaking helped ensure appropriate cBathy results near the shoreline and thus a narrow gap between the cBathy and SfM results, reducing the interpolation distance required. To improve results in this region, or to improve quality of bathymetry results in less ideal conditions, data assimilation [21] of the combined topography and wave speeds may yield improved depths near the shoreline.

\section{B. Example Product Application}

Seamless topo-bathymetric data are desirable for a number of potential applications, including monitoring the volume of sediment contained in a nearshore system or quantifying shoreline change, either following a beach nourishment effort or to quantify storm impacts, for example. To assess the applicability of these data products to calculate sediment volumes across the beach and surf zone, we compared the estimated total volume of sediment above $-8 \mathrm{~m}$ NAVD8 8 for 21 cross-shore profiles [black dotted lines, Fig. 9(a)] between the GPS-Hydro survey collected by the LARC [black circles, Fig. 9(b)] and the UAS-derived DSM [colors, Fig. 9(a); blue circles, Fig. 9(b)]. UAS and LARC-derived profile volumes compared well [Fig. 9(b)], with an RMSD of $69.3 \mathrm{~m}^{3} / \mathrm{m}$, with the UAS slightly underestimating volumes by $-18.3 \mathrm{~m}^{3} / \mathrm{m}$ (bias). The one exception occurred near the FRF pier where the UAS underestimated the water depths [see Fig. 7(c)], leading to an over-estimation in profile volume. With the exception of this region, the UAS-derived profile volumes captured similar alongshore variability compared to the LARC. Note that the UAS topo-bathymetric data provide elevations at high resolution over the entire domain, potentially reducing any errors that may be associated with aliasing due to transect location and spacing, and therefore could be used to make more complete estimations of regional sediment volumes. In addition, we also compared the cross-shore position of the 0-m NAVD88 shoreline between the gridded LARC survey [black line, Fig. 9(a)] and the UAS [not shown explicitly; look for white colors in Fig. 9(a)]. Agreement between the two shorelines was excellent $(\mathrm{RMSD}=2.77 \mathrm{~m}$; bias $=-1.25 \mathrm{~m}$ ). The ability to extract a datum-based shoreline position (versus a feature-based shoreline) is critical for reliable estimates of shoreline change [53], [54].

\section{Payload Applicability + CONOPS}

The presented results demonstrate that the multicamera payload can accurately provide nearshore topography, bathymetry, and long dwell $(7 \mathrm{~min})$ surf-zone image products for $1 \mathrm{~km}$ of coastline aboard a small multirotor UAS. In this configuration, the system is more efficient than utilizing a single camera multirotor system [28], as to measure topography and bathymetry with a single camera multirotor system (herein termed "hover" CONOPS), two types of flights would be required: 1) at least two transect flights along the coast for SfM analysis with nadir imagery ( $5 \mathrm{~min}$ ) and 2) up to three 7 -min hovers with oblique imagery for the surf-zone imagery and bathymetry estimates. The multicamera configuration presented in this paper therefore requires slightly less time (15 versus $26 \mathrm{~min}$ ) than would be captured by a single camera CONOPs. The presented payload's efficiency and advantage grows for larger stretches of coastline (discussed below), particularly if used onboard a fixed wing UAS or quadcopter with increased battery efficiency or capacity, respectively.

Fig. 10 explores the applicability of this multicamera payload system for longer stretches of coastline utilizing fixed wing and multirotor platforms. Flight time, or battery life, for fixed wing systems is estimated at 53 min for speeds ranging from 15 to $18 \mathrm{~m} / \mathrm{s}$ assuming a Birdseye FireFly6 Pro platform and constant performance curve [55]. Multirotor flight time is estimated at 20-30 min with an assumed performance curve [56], [57] for a DJI Matrice 600. Elevation is set to $122 \mathrm{~m}$ (400 ft; limited by FAA Part 107 guidelines in the United States) to maximize dwell time, which results in an FOV in 
(a)

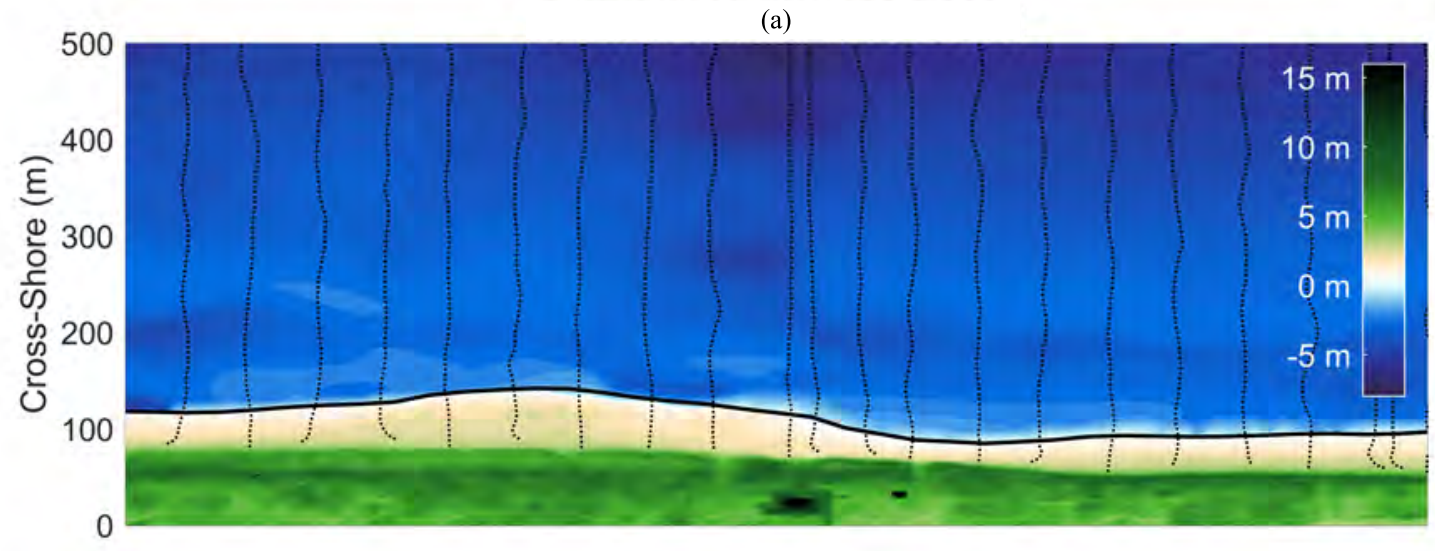

(b)

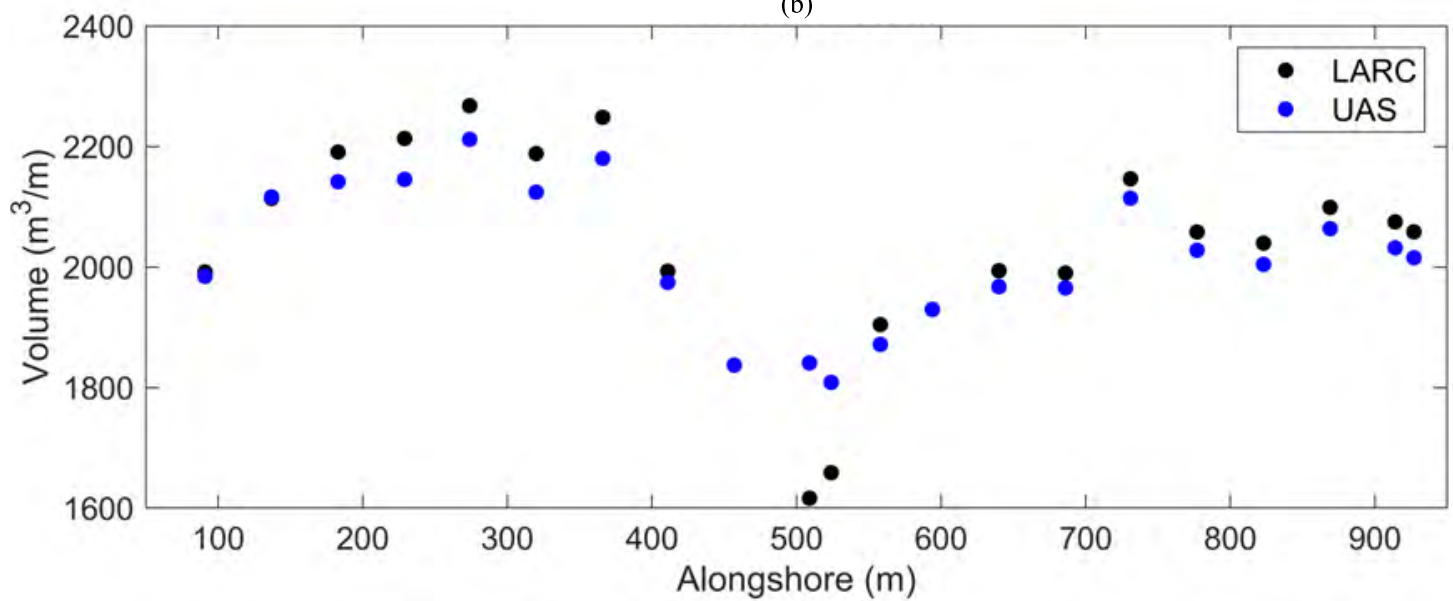

Fig. 9. Example calculation of beach and surf-zone volume along the FRF study site. (a) Topo-bathymetric DEM (colors) produced from the UAS over the FRF domain (cross-shore versus alongshore) with locations of the LARC acoustic survey overlain (black dotted line) and the LARC derived shoreline (solid black line). (b) Profile volume above the -8 -m contour along each LARC transect for the LARC (black) and UAS (blue).

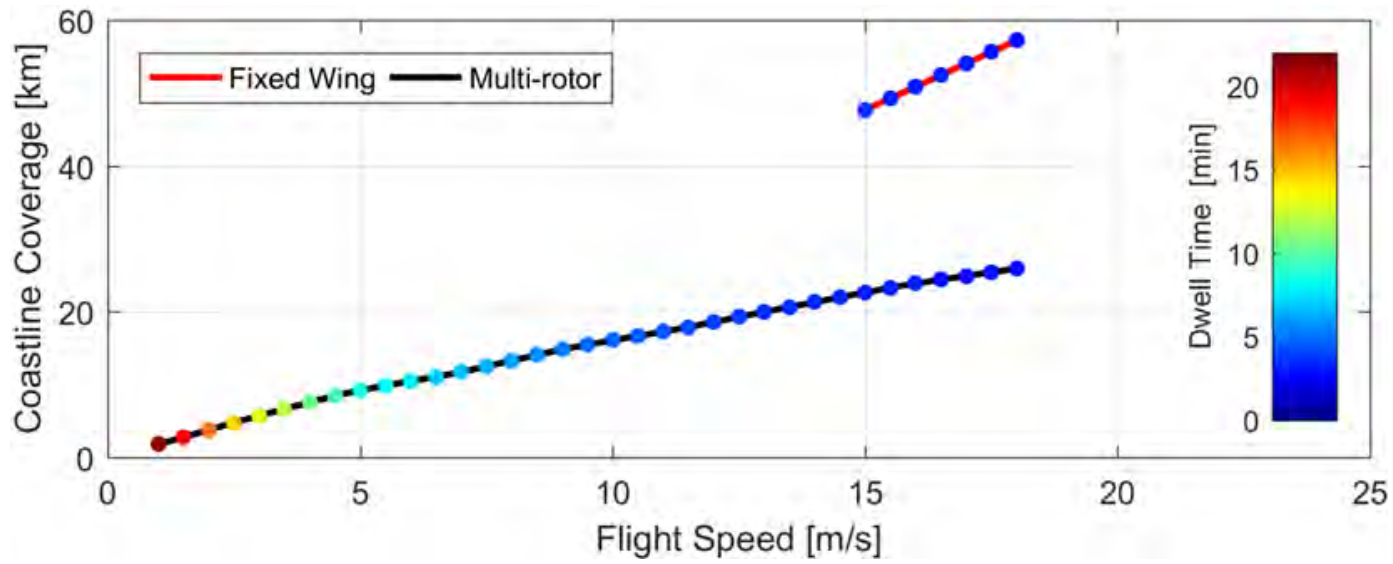

Fig. 10. Dwell time (colors) for different coastline coverage and flight speeds for long-distance fixed wing (red) and multirotor UAS (black line) flights at an altitude of $122 \mathrm{~m}$.

the cross-shore and alongshore of $700 \mathrm{~m}$ and $2 \mathrm{~km}$. This elevation retains the necessary camera pixel resolution for $\mathrm{SfM}(<0.4 \mathrm{~m} /$ pix in the down camera) and cBathy $(<5 \mathrm{~m} / \mathrm{pix})$ processing.

For the multirotor system (black line, Fig. 10), practical coastline coverage spans from $1.82 \mathrm{~km}$ with a 21 -min dwell time to $26 \mathrm{~km}$ with a 2.8 -min dwell time. For dwell times similar to those presented in this paper $(7 \mathrm{~min})$, a multirotor system could cover $11 \mathrm{~km}$ at $6.5 \mathrm{~m} / \mathrm{s}$ in $28 \mathrm{~min}$. This is much more efficient than the hover CONOPS discussed earlier, which would take $26 \min$ to cover $1 \mathrm{~km}$. The fixed wing CONOPs (red line, Fig. 10) has a much smaller window of 
operation due to minimum speed requirements, and at this elevation could only provide dwell times of 3.5-2.9 min, but for much larger stretches of coastline (48-57 km, respectively). Although cBathy analysis performs better with increased dwell time, work has been conducted to improve algorithm efficiencies for short dwell times and could explored to improve short dwell results if needed [26]. Finally, for both CONOPs, a UAS pilot and spotter would have to follow both platforms at similar speeds to maintain radio transmission/sightline range, which may be more challenging for the longer coastline coverage.

Another challenge for longer coastline collects is the placement of GCPs. Longer coastlines require more GCPS and thus more time to place, survey, and retrieve them. This can be alleviated with the use of a high end GNSS-INS aboard the UAS platform. The Appendix explores the use of a GNSS-INS system in lieu of GCPS for the presented UAS and methodology (Fig. 2). Our results suggest that this methodology is a good alternative and appropriate for applications where horizontal and bathymetric accuracy is acceptable within $1 \mathrm{~m}$.

\section{CONCLUSION}

A low-cost ( U.S. \$2500), four-camera system mounted onboard a multirotor UAS was utilized to accurately quantify topography and bathymetry along $1-\mathrm{km}$ stretches of coast in Duck, NC, USA and Virginia Beach, VA, USA. In addition, the system provided long-dwell imagery of the coastline enabling mapping of nearshore wave breaking and inundation extents along the open coast. The unique wide FOV generated by the multicamera system in combination with forward motion flight allowed for the merging of two processing approaches of coastal imagery from one data set: 1) SfM, which inherently requires motion and different views of a stationary scene to generate topography and 2) the Argus suite of processing tools [42] which exploits long-dwell imagery of moving waves to quantify nearshore parameters. Data products were evaluated relative to vessel-based acoustic surveys of nearshore bathymetry at both sites and terrestrial lidar scans of beach and dune topography for the FRF field site in Duck, NC, USA. For both sites, bathymetry results showed good agreement to control $(\mathrm{RMSE}=0.34$ and $0.17 \mathrm{~m}$; bias $=$ -0.05 and $0.06 \mathrm{~m}$ in FRF and VA Beach, respectively), and good agreement to lidar topography $(\mathrm{RMSE}=0.26 \mathrm{~m}$; bias $=-0.05 \mathrm{~m}$ ) at the FRF. Errors were largest near the shoreline for the bathymetry and on the heavily vegetated dune crests. Calculation of NAVD88 0-m shoreline position and total profile volume along the FRF site compared well to a traditional topo-bathymetric survey conducted with the LARC, demonstrating the utility of the combined data sets. While all of the above results utilized ground-control-points to optimize the UAS trajectory and point-cloud, the analysis included in the Appendix showed that similar levels of accuracy (slight increases in RMSE) could be achieved with significantly less collection and processing time by including an on-board GNSS-INS system, which would be advantageous if surveying large stretches of coastline. Finally, a variety of potential CONOPS onboard different multirotor and fixed wing platforms were explored and the time-savings calculated relative to using a single camera system to collect the same data.

\section{APPENDIX \\ UTILIZATION OF ON-BOARD GPS-INS VERSUS SURVEYED GROUND CONTROL}

The results from the FRF and VA Beach flights in Section V were georectified utilizing GCPs surveyed by a land-based RTK-GPS system and processed according to methodology outlined in Fig. 2. Although utilizing GCPs is common practice and accurate, placement is not practical or possible in all coastal environments (narrow beaches, structurally unsound jetties, etc.). In addition, GCP placement is time-consuming for long stretches of coastline $(>2 \mathrm{~km})$. In lieu of GCPs, a GPS-INS system onboard the UAS can provide camera EOs. Prior to the VA Beach flight, a high-end GPS-INS system (Applanix APX-15) was installed aboard the UAS. The results in Section V did not utilize the APX-15 output; however, this section will show data products produced with the APX-15 output and no GCPs. Specifically, this section compares results for the two different processing methods at the VA Beach field site: 1) the traditional GCP method as outlined in Fig. 2 (GCP Method) and 2) utilization of the APX-15 without GCPs (seed method). Direct rectification of the surf-zone imagery from APX output is not evaluated since Photoscan is required to perform the SfM analysis for the pointcloud regardless.

\section{A. GPS-INS System and Operation}

The Applanix APX-15 is an original equipment manufacturer (OEM) GNSS-INS single board costing approximately U.S. $\$ 15000$. The board, measuring $60 \times 67 \mathrm{~mm}^{2}$, fti inside the original UAS payload and was powered independently by a $12-\mathrm{V} 700-\mathrm{mAH}$ rechargeable lithium battery secured on top of the UAS, providing approximately $60 \mathrm{~min}$ of operation. The APX-15 utilizes a Trimble Av14 L1-L2 antenna that is secured to the bow. The APX-15 system runs independently of the GoPro cameras, Teensy microcontroller, and X8+ autopilot. The only connection is the PPS and NMEA (RS232 Serial) output between the Teensy and APX-15, replacing the Adafruit Ultimate GPS/Antenna. The APX-15, Av14 antenna, battery, and cabling added $215 \mathrm{~g}$ of extra weight.

In-flight CONOPs are not altered; the only differentiations are periods at take-off and landing. Before take-off and after landing, the APX-15 must remain stationary for at least 3 min as per recommendation of the manufacturer. In addition, it is suggested by the manufacturer to do s-turn and high velocity maneuvers before collection to initialize the INS system. Testing indicated that the flight from the takeoff to the first waypoint was sufficient to initialize the INS system, and was therefore not performed. This was beneficial as high velocity maneuvers would have reduced the amount of time that the UAS would have been flying the mapping portion of the mission.

\section{B. Seed-Method Processing}

APX-15 output data from the VA Beach flight is postprocessed with Applanix POSPac UAS 8.0, with computed 
TABLE III

Comparison of Camera eO for VA Beach Flight Between GPS+APX Processing Methods and aPX Output. Metrics Calculated on Differences Between eO Outputs. Values in Brackets Are the Absolute Minimum Values Across All Four Cameras, Unbracketed Values Are the Absolute Maximums

\begin{tabular}{|c|c|c|c|c|c|c|c|}
\hline \multicolumn{2}{|c|}{$\begin{array}{l}\text { [absolute minimum] } \\
\text { absolute maximum }\end{array}$} & \multirow{2}{*}{$\begin{array}{c}\mathrm{X}[\mathrm{M}] \\
{[0.12]} \\
0.17\end{array}$} & \multirow{2}{*}{$\begin{array}{c}\mathrm{Y}[\mathrm{M}] \\
{[0.05]} \\
0.29\end{array}$} & \multirow{2}{*}{$\begin{array}{c}\mathrm{Z}[\mathrm{M}] \\
{[0.11]} \\
0.32\end{array}$} & \multirow{2}{*}{$\begin{array}{c}\omega\left[^{\circ}\right] \\
{[0.37]} \\
0.67\end{array}$} & \multirow{2}{*}{$\begin{array}{c}\varnothing\left[^{\circ}\right] \\
{[0.29]} \\
1.71\end{array}$} & \multirow{2}{*}{$\begin{array}{c}\kappa\left[^{0}\right] \\
{[0.58} \\
1.94\end{array}$} \\
\hline $\begin{array}{l}\text { Standard } \\
\text { Deviation }\end{array}$ & GCP-APX & & & & & & \\
\hline & Seed-GPS & $\begin{array}{c}{[0.07]} \\
0.22\end{array}$ & $\begin{array}{c}{[0.08]} \\
0.25\end{array}$ & $\begin{array}{c}{[0.15]} \\
0.28\end{array}$ & $\begin{array}{c}{[0.14]} \\
0.69\end{array}$ & $\begin{array}{c}{[0.01]} \\
0.14\end{array}$ & $\begin{array}{c}{[0.04]} \\
0.29\end{array}$ \\
\hline Bias & Seed-GCP & $\begin{array}{c}{[-0.01]} \\
-0.08\end{array}$ & $\begin{array}{c}{[-0.02]} \\
0.25\end{array}$ & $\begin{array}{l}{[-0.3]} \\
-0.26\end{array}$ & $\begin{array}{c}{[-0.18]} \\
0.39\end{array}$ & $\begin{array}{c}{[-0.14]} \\
0.10\end{array}$ & $\begin{array}{c}{[-0.01]} \\
0.19\end{array}$ \\
\hline
\end{tabular}

Metrics calculated on differences between EO outputs. Values in brackets are the absolute minimum values across all four cameras, un-bracketed values are the absolute maximums.

orientation and positions at $100 \mathrm{~Hz}$ with mean reported accuracies of $0.02 \mathrm{~m}, 0.04 \mathrm{~m}, 0.05^{\circ}$, and $0.9^{\circ}$ for the horizontal position, elevation, roll/pitch, and heading, respectively. These position and orientation estimates of the airframe were then time synchronized with the GoPro imagery, as described in Section III-A, and used as an initial estimate of the camera EO in Photoscan with an estimated accuracy of $0.5 \mathrm{~m}$ and $2^{\circ}$. The orientation of each camera relative to the vehicle coordinate system is input into Photoscan Camera Properties as per Table I. No GCPs were utilized in Photoscan, and the remaining $\mathrm{SfM}$ processing was performed as described in Sections III-C-III-E.

\section{Resultant Camera Extrinsics}

Camera EOs output by Photoscan for the GCP and Seed method are quantitatively and qualitatively compared with the postprocessed APX-15 output in Table III and Fig. 11 respectively. The seed and GCP methods have small bias and RMSD for all EO position $(<0.32 \mathrm{~m})$ and orientation $\left(<0.7^{\circ}\right)$ parameters; suggesting the two methods converged to similar solutions in Photoscan. The GCP EO also had small bias and RMSD but larger RMSD for EO orientations $\left(1^{\circ}-2^{\circ}\right)$ when compared to the APX-15 output. This is due to the approximate boresighting between the cameras and APX-15 to determine the camera orientations. Despite utilizing CAD software to construct the mount and calculating boresights, assembly is not exact. Thus, there is a relatively constant offset between the Photoscan outputs and APX as shown in Fig. 11(d)-(f).

\section{Surf-Zone Imagery}

Fig. 12 highlights differences between the seed and GCP EO parameters in the downstream orthophotos. Fig. 12(a)-(c) display cross-shore pixel intensity (grayscale) transects for the Timex (a), Brightest (b), and Snapshot (c) orthophotos for each method (Seed: black, GCP: color). Transect positions overlay the example seed snapshot in Fig. 12(e). For all three transects the Timex and Brightest comparisons have high correlation $\left(R^{2}>0.99\right)$ in the submerged areas. Both methods position major surfzone features such as the breaker zone [Fig. 12(b)], cross-shore $350 \mathrm{~m}$, green transect] and shorelines [Fig. 12(b)], cross-shore 350-m-red transect) in the same location. Topographic features (cross-shore position $<400 \mathrm{~m}$ ) from both methods are also congruent.

There is slightly less correlation between the seed and GCP methods for submerged areas in the snapshot profiles in Fig. 12(c) $\left(R^{2}>0.98\right)$. This is particuarly apparent offshore where individual waves appear staggered between methods. A windowed $(50 \mathrm{~m})$ cross correlation analysis is computed for the pixel intensity along each transect. The shift (lag) with the highest correlation for each pixel is plotted in Fig. 12(d) with a cutoff corelation of 0.9 . The shift distance between the GCP and seed method increases offshore for all transects, indicating the seed method placed features more offshore than the GCP method. This indicates that the discrepency is due to a difference in elelvation or orientation, rather than horizontal position because the discrepency grows with distance form the cameras. This trend is clearest with the green transect, looking perpendicular into the wave direction and along the centerline of the side camera. The northern blue and southern red transects have the highest and lowest shifts offshore respectively. This is in part due to the relative wavelengths in each area [Fig. 12(e)]. Correlation analysis for longer wavelengths are less sensitve to 1-3 $\mathrm{m}$ shifts since they are less steep and have a weaker and a more diffuse optical signature [28]. All transects show that the growing offset is important across the entire study area, and while stretching wavelengths may not affect nearshore surfzone imagery (breaker zone, etc.), they will affect bathymetry estimates from algorithms utilizing optical wave properties.

\section{E. DSMS}

Fig. 13 highlights the differences between the DSMs produced by the seed and GCP method. The reported Photoscan RMSD of the dense point clouds with the GCPs is 0.01 and $0.63 \mathrm{~m}$ for the GCP and seed method, respectively. 
(a)

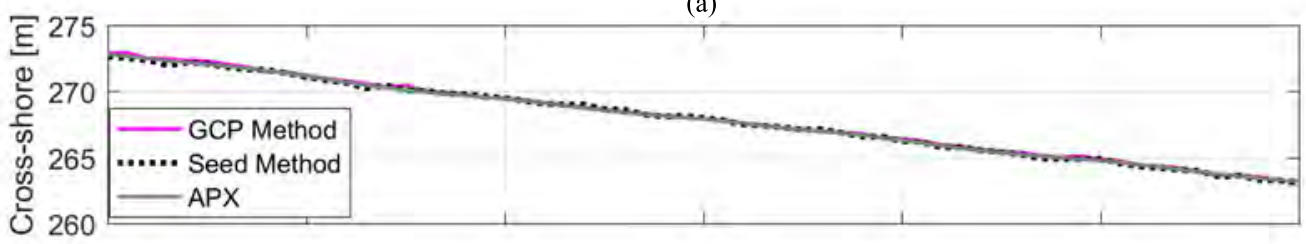

(b)

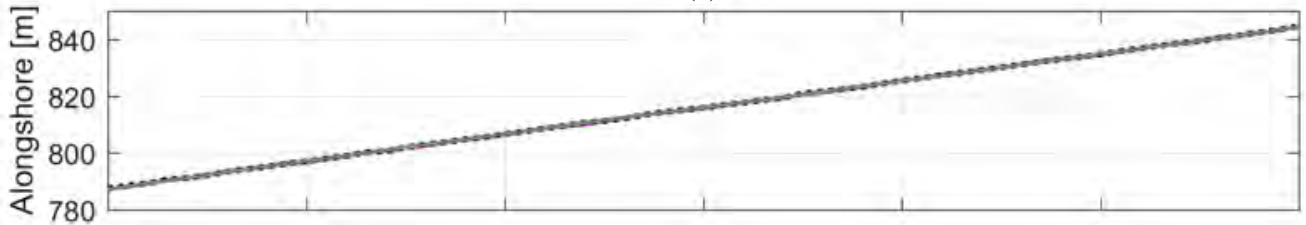

(c)

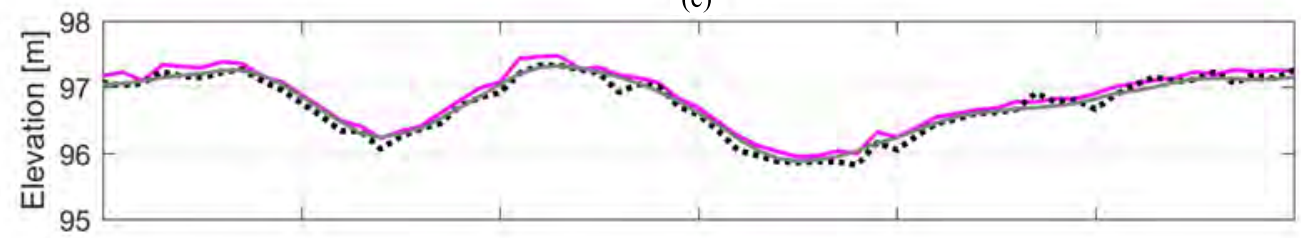

(d)

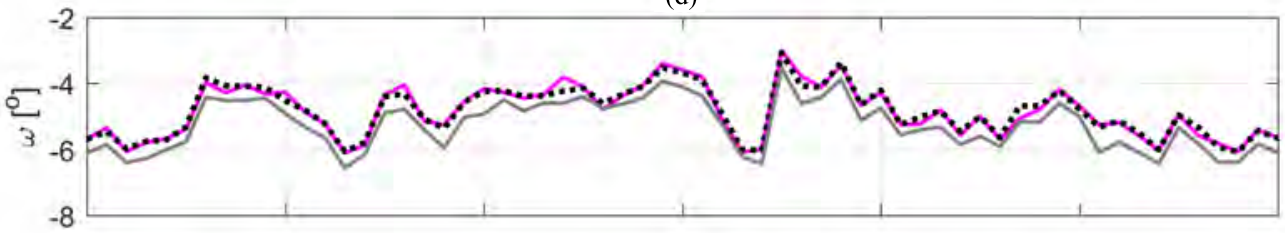

(e)

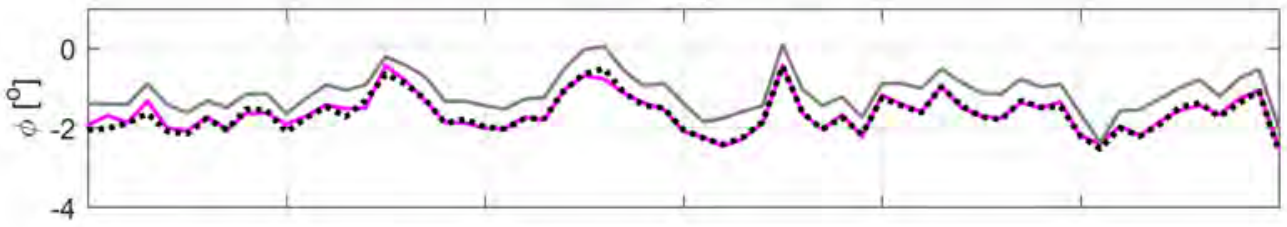

(f)

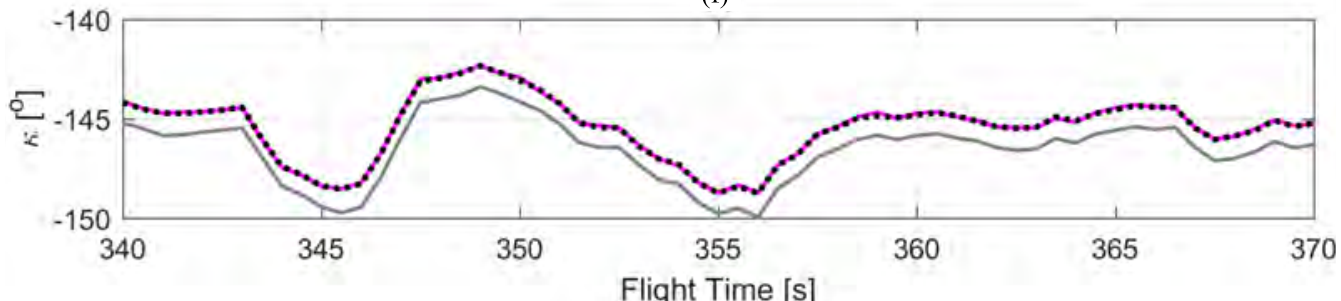

Fig. 11. Comparison of down camera EO for VA Beach flight between GPS+APX processing methods and APX output. (a)-(c) Down camera position in local coordinates. (d)-(f) Down camera orientation. For visual reference: down camera $\omega$ is analogous to pitch of the UAS $\left(+\omega=\mathrm{CCW}\right.$ about $\left.\mathrm{Y}_{\mathrm{V}}\right)$; down camera $\emptyset$ is analogous to roll of the UAS $\left(+\emptyset=\mathrm{CCW} \mathrm{X}_{\mathrm{V}}\right)$; and down camera $\kappa$ is analogous to heading of the UAS $\left(+\kappa=\mathrm{CW}\right.$ about $\left.\mathrm{Z}_{\mathrm{V}}\right)$.

It is important to remember the seed method pointcloud is not optimized using GCPs, so whereas the RMSD of the GCP method is a measure of optimization fit, the RMSD of the seed method is a measure of ground truth accuracy. The RMSD of the topography between the two methods is $0.62 \mathrm{~m}$ with most differences $<2 \mathrm{~m}$ and the seed method with a bias of $-0.09 \mathrm{~m}$. Larger elevation differences are due to slight horizontal shifts in areas with steep gradients such as vertical structures or trees. However, general features such as dune crest elevation and shape are resolved similarly [Fig. 12(b)]. There is no clear indicator why the seed method topography is on average higher in northern study area lower in the southern study area other than that errors from feature matching between adjacent images are compounded and there is no ground control to constrain the seed-method solution.

The seed and GCP bathymetry are in good agreement with a low RMSD of $0.35 \mathrm{~m}$ and the seed bias is $-0.10 \mathrm{~m}$. This is congruent with the fact that the seed method stretches offshore features, creating longer wavelengths offshore. Longer wavelengths for the same period waves increase the 
(a)

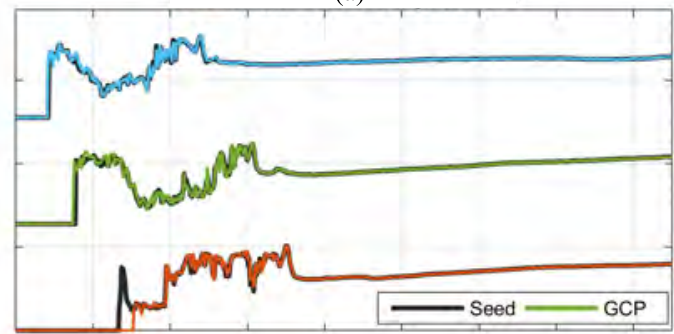

(b)

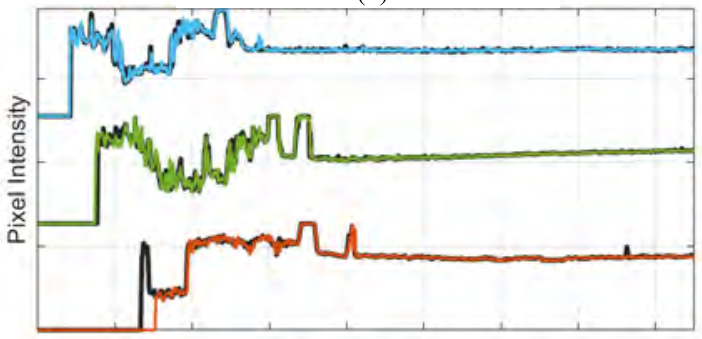

(c)

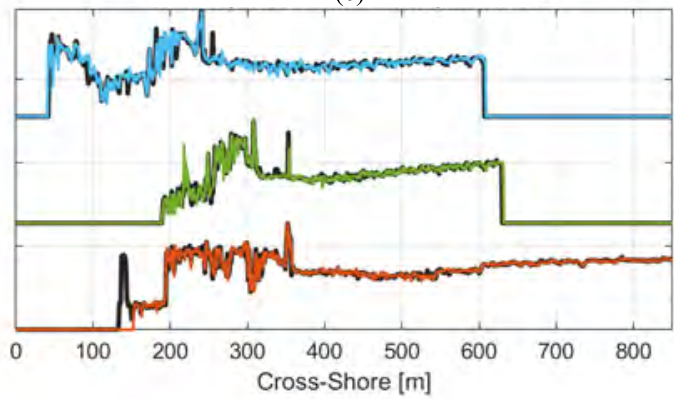

(d)

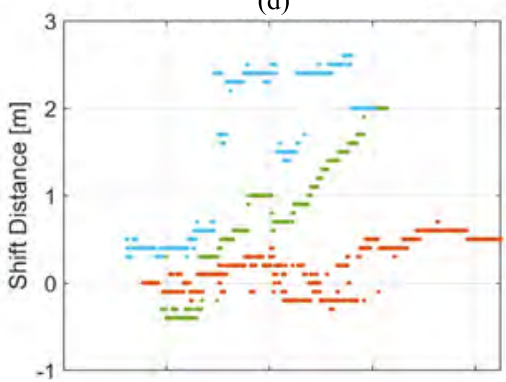

(e)

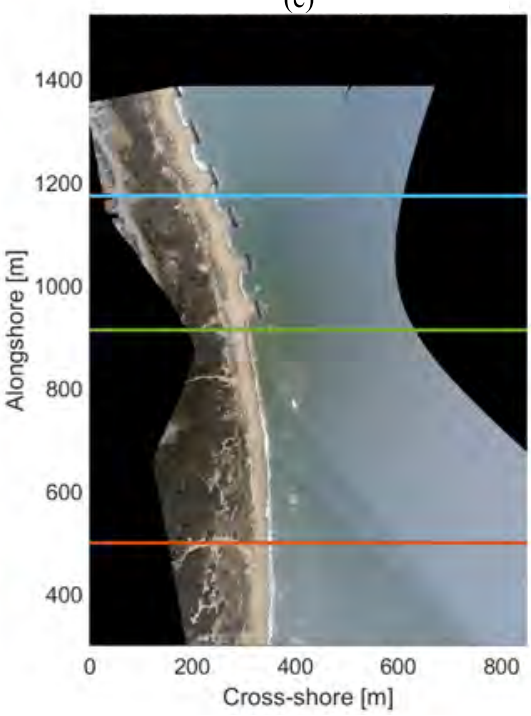

Fig. 12. Differences in geo-rectified imagery between seed and GCP methods. Cross-shore profiles of gray scale pixel intensities for (a) Timex, (b) Brightest, and (c) example snapshot orthophotos. Black/colored lines refers to seed/GCP method. Colored lines match profiles in (d) and (e). (d) Cross-shore shift of GCP method pixel intensity profiles to provide maximum correlation with seed method. Correlation calculated over 50-m windows with $1 \mathrm{~m} /$ pixel resolution using example snapshot profiles in (c). Positive shifts indicate that seed-method features are located further offshore than GCP features. (e) Example seed method snapshot used in calculations for (c) and (d).

(a)

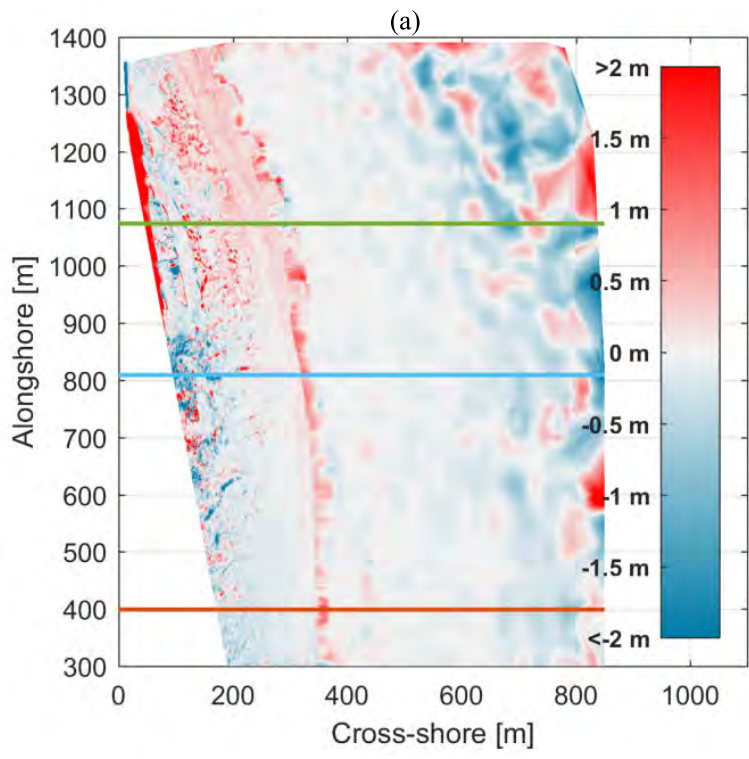

(a)

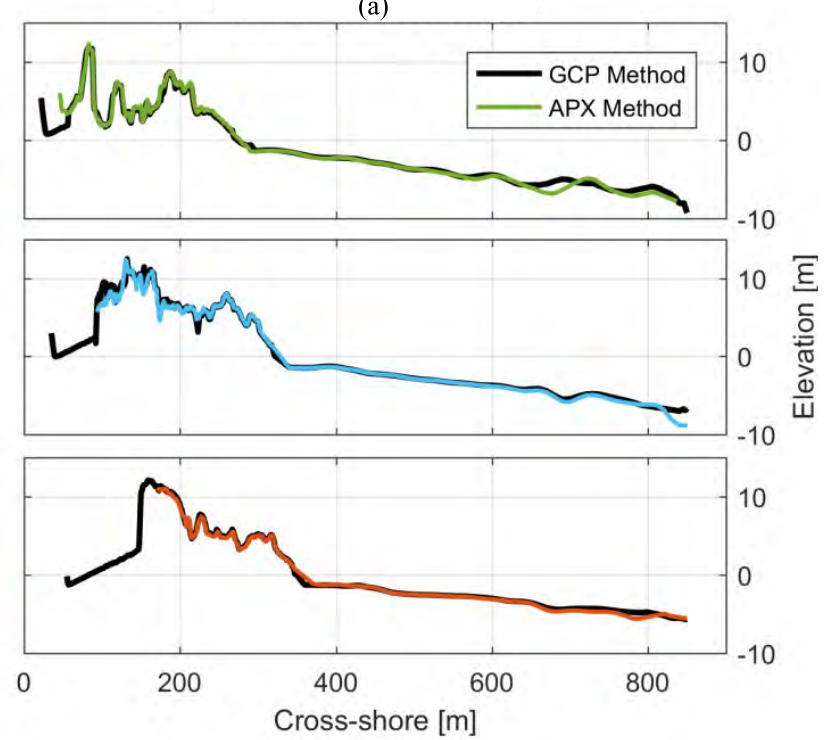

Fig. 13. Difference in DSM elevations at VA for GCP and seed methods in local coordinate system. (a) Elevation difference between seed method DSM and GPS method DSM at 1-m resolution. Red indicates seed DSM has higher elevations, and blue indicates seed DSM has lower elevations than GCP method. Colored lines refer to profiles depicted in (b). (b) Cross-shore profiles estimated by GCP method (black) and seed method (colored). Elevations in NAVD88.

celerity estimates and therefore depths. Largest discrepancies are offshore (Fig. 13) where orthophoto shifts were largest as well [Fig. 12(d)]. Discrepancies at the shoreline are differences in interpolation extents between the topography and bathymetry results; the seed method did not resolve as large as a cross-shore topographic extent as the GCP method. 


\section{F. Discussion}

Utilization of the high-end APX-15 GNSS-INS in the presented UAS platform and processing workflow in lieu of GCPs provided similar results with significantly reduced collection and processing times. GCP positioning and surveying in the field requires two additional hours and the seed-method workflow required $36 \mathrm{~h}$ compared to the GCP Method's 86. In processing, most time saved was during Steps $2-4$ in Fig. 2 by 45 h. Although time was reduced with the seed method, accuracy decreased as well. Seed topography is slightly displaced; however, major coastal features such as dune crests were resolved similar to the GCP method. Bathymetry too was accurately resolved, with larger discrepancies offshore where differences in camera extrinsics are magnified. Thus, utilization of a high-end GNSS-INS without GCPs is suggested for this system for applications where horizontal and bathymetric accuracy is acceptable within $1-2 \mathrm{~m}$ and quick processing is necessary.

\section{ACKNOWLEDGMENT}

The authors would like to thank A. Renaud for help collecting the data at both sites and for coordinating field logistics during the VA Beach experiment. They would like to thank J. Pipes, B. Ledford, M. Priesser, R. Mitchell, D. Freer, K. Hathaway, and M. Forte for their hard work to deploy and maintain the in situ gauges, to perform nearshore bathymetric surveys, and to maintain the Argus Tower and cameras at the FRF. They would also like to thank Dr. R. Holman and J. Stanley at Oregon State University for their expert advice on Argus and cBathy and discussion on UAS.

\section{REFERENCES}

[1] N. A. Elko, R. A. Holman, and G. Gelfenbaum, "Quantifying the rapid evolution of a nourishment project with video imagery," J. Coastal Res., vol. 214, pp. 633-645, Jul. 2005.

[2] K. T. Holland, D. M. Lalejini, S. D. Spansel, and R. A. Holman, "Littoral environmental reconnaissance using tactical imagery from unmanned aircraft systems," Ocean Sens. Monit. II, vol. 7678, Apr. 2010, Art. no. 767806-8

[3] H. M. Wadman, J. E. McNinch, and A. Foxgrover, Military Geosciences in the Twenty-First Century, vol. 22. Boulder, CO, USA: Geological Society of America, 2014.

[4] S. Fleming, T. Jordan, M. Madden, E. L. Usery, and R. Welch, "GIS applications for military operations in coastal zones," ISPRS $J$ Photogramm. Remote Sens., vol. 64, no. 2, pp. 213-222, Mar. 2009.

[5] W. A. Birkemeier and C. Mason, "The CRAB: A unique nearshore surveying vehicle," J. Surv. Eng., vol. 110, no. 1, pp. 1-7, Mar. 1984.

[6] W. A. Birkemeier, M. Forte, and H. C. Miller, "New mid-atlantic observations of the depth of closure," in Proc. 30th Int. Conf. Coastal Eng., May 2007, pp. 3404-3416.

[7] J. P. Dugan, W. D. Morris, K. C. Vierra, C. C. Piotrowski, G. J. Farruggia, and D. C. Campion, "Jetski-based nearshore bathymetric and current survey system on JSTOR," J. Coast. Res., vol. 17, no. 4, pp. 900-908, May 2001.

[8] B. C. Ludka, R. T. Guza, W. C. O'Reilly, and M. L. Yates, "Field evidence of beach profile evolution toward equilibrium," J. Geophys. Res. Oceans, vol. 120, no. 11, pp. 7574-7597, Nov. 2015.

[9] N. G. Plant, K. T. Holland, and J. A. Puleo, "Analysis of the scale of errors in nearshore bathymetric data," Mar. Geol., vol. 191, nos. 1-2, pp. 71-86, Nov. 2002.

[10] J. L. Irish and W. J. Lillycrop, "Scanning laser mapping of the coastal zone: The SHOALS system," ISPRS J. Photogramm. Remote Sens., vol. 54, pp. 123-129, Jul. 1999.

[11] A. H. Sallenger et al., "Evaluation of airborne topographic lidar for quantifying beach changes," J. Coast. Res., vol. 19, no. 1, pp. 125-133, Jan. 2003 .
[12] G. Tuell, K. Barbor, and J. Wozencraft, "Overview of the coastal zone mapping and imaging lidar (CZMIL): A new multisensor airborne mapping system for the U.S. army corps of engineers," Proc. SPIE, vol. 7695, pp. 76950R-76950R-8, Sep. 2018.

[13] K. T. Holland and M. L. Palmsten, "Remote sensing applications and bathymetric mapping in coastal environments," in Advances in Coastal Hydraulics, Singapore: World Scientific, 2018, pp. 375-411.

[14] T. C. Lippmann and R. A. Holman, "Quantification of sand bar morphology: A video technique based on wave dissipation," J. Geophys. Res., vol. 94, no. C1, p. 995, Jan. 1989.

[15] K. T. Holland, R. A. Holman, T. C. Lippmann, J. Stanley, and N. Plant, "Practical use of video imagery in nearshore oceanographic field studies," IEEE J. Ocean. Eng., vol. 22, no. 1, pp. 81-91, Sep. 1997.

[16] J. P. Dugan, C. C. Piotrowski, and J. Z. Williams, "Water depth and surface current retrievals from airborne optical measurements of surface gravity wave dispersion," J. Geophys. Res., vol. 106, no. C8, p. 16903, Aug. 2001.

[17] M. C. Haller and D. R. Lyzenga, "Comparison of radar and video observations of shallow water breaking waves," IEEE Trans. Geosci. Remote Sens., vol. 41, no. 4, pp. 832-844, Apr. 2003.

[18] T. C. Lippmann and R. A. Holman, "The spatial and temporal variability of sand bar morphology," J. Geophys. Res., vol. 95, no. C7, Jul. 1990, Art. no. 11575 .

[19] N. G. Plant, K. T. Holland, and M. C. Haller, "Ocean wavenumber estimation from wave-resolving time series imagery," IEEE Trans Geosci. Remote Sens., vol. 46, no. 9, pp. 2644-2658, Sep. 2008.

[20] R. Holman, N. Plant, and T. Holland, "cBathy: A robust algorithm for estimating nearshore bathymetry," J. Geophys. Res. Oceans, vol. 118 no. 5, pp. 2595-2609, May 2013.

[21] A. van Dongeren, N. Plant, A. Cohen, D. Roelvink, M. C. Haller, and P. Catalán, "Beach Wizard: Nearshore bathymetry estimation through assimilation of model computations and remote observations," Coastal Eng., vol. 55, no. 12, pp. 1016-1027, 2008.

[22] M. W. J. Smit et al., "The role of video imagery in predicting daily to monthly coastal evolution," Coast. Eng., vol. 54, nos. 6-7, pp. 539-553, Jun. 2007.

[23] G. W. Wilson, H. T. Ózkan-Haller, and R. A. Holman, "Data assimilation and bathymetric inversion in a two-dimensional horizontal surf zone model," J. Geophys. Res. Oceans, vol. 115, no. 12, pp. 1-17, 2010.

[24] G. W. Wilson, H. T. Özkan-Haller, R. A. Holman, M. C. Haller, D. A. Honegger, and C. C. Chickadel, "Surf zone bathymetry and circulation predictions via data assimilation of remote sensing observations," J. Geophys. Res., Oceans, vol. 119, no. 3, pp. 1993-2016, 2014.

[25] C. C. Piotrowski and J. P. Dugan, "Accuracy of bathymetry and current retrievals from airborne optical time-series imaging of shoaling waves," IEEE Trans. Geosci. Remote Sens., vol. 40, no. 12, pp. 2606-2618, Dec. 2002.

[26] R. A. Holman, K. T. Holland, D. M. Lalejini, and S. D. Spansel, "Surf zone characterization from unmanned aerial vehicle imagery," Ocean Dyn., vol. 61, no. 11, pp. 1927-1935, Sep. 2011.

[27] M. I. Vousdoukas, G. Pennucci, R. A. Holman, and D. C. Conley, "A semi automatic technique for rapid environmental assessment in the coastal zone using small unmanned aerial vehicles (SUAV)," J. Coast. Res., vol. 11, no. 64, pp. 1755-1759, Jan. 2011.

[28] R. A. Holman, K. L. Brodie, and N. J. Spore, "Surf zone characterization using a small quadcopter: Technical issues and procedures," IEEE Trans. Geosci. Remote Sens., vol. 55, no. 4, pp. 2017-2027, Apr. 2017.

[29] J. Chandler, "Effective application of automated digital photogrammetry for geomorphological research," Earth Surf. Process. Landforms, vol. 24, no. 1, pp. 51-63, Jan. 1999.

[30] I. Colomina and P. Molina, "Unmanned aerial systems for photogrammetry and remote sensing: A review," ISPRS J. Photogram. Remote Sens., vol. 92, pp. 79-97, Jun. 2014.

[31] N. Snavely, S. M. Seitz, and R. Szeliski, "Photo tourism," ACM Trans. Graph., vol. 25, no. 3, p. 835, Jul. 2006 .

[32] M. J. Westoby, J. Brasington, N. F. Glasser, M. J. Hambrey, and J. M. Reynolds, "Structure-from-Motion' photogrammetry: A low-cost, effective tool for geoscience applications," Geomorphology, vol. 179, pp. 300-314, Dec. 2012.

[33] F. Mancini, M. Dubbini, M. Gattelli, F. Stecchi, S. Fabbri, and G. Gabbianelli, "Using unmanned aerial vehicles (UAV) for highresolution reconstruction of topography: The structure from motion approach on coastal environments," Remote Sens., vol. 5, no. 12, pp. 6880-6898, Dec. 2013. 
[34] S. Harwin and A. Lucieer, "Assessing the accuracy of georeferenced point clouds produced via multi-view stereopsis from unmanned aerial vehicle (UAV) imagery," Remote Sens., vol. 4, no. 6, pp. 1573-1599, May 2012.

[35] I. L. Turner, M. D. Harley, and C. D. Drummond, "UAVs for coastal surveying," Coastal Eng., vol. 114, pp. 19-24, Aug. Aug. 2016.

[36] J. Vautherin et al., "Photogrammetric accuracy and modeling of rolling shutter cameras," ISPRS Ann. Photogramm. Remote Sens. Spat. Inf. Sci., vol. 3, no. 3, pp. 139-146, Apr. 2016.

[37] M. R. James and S. Robson, "Mitigating systematic error in topographic models derived from UAV and ground-based image networks," Earth Surf. Process. Landforms, vol. 39, no. 10, pp. 1413-1420, Aug. 2014.

[38] Agisoft PhotoScan User Manual Professional Edition, Version 1.4, Agisoft, St. Petersburg, Russia, 2018.

[39] D. C. Brown, "Decentering distrotion of lenses," Photogramm. Eng., vol. 32, no. 3, pp. 44-462, Oct. 1966.

[40] K. Zuiderveld, "Contrast Limited Adaptive Histograph Equalization," in Graphic Gems IV, New York, NY, USA: Academic, 1994, pp. 474-485.

[41] A. L. LeWinter, Characterization of the Overlook Crater and Lava Lake of Kilauea Volcano Through Terrestrial Laser Scanning, University of Northern Colorado, Greeley, Colorado, 2014.

[42] R. A. Holman and J. Stanley, "The history and technical capabilities of argus," Coast. Eng., vol. 54, no. 6, pp. 477-491, Jun./Jul. 2007.

[43] M. F. Forte, W. A. Birkemeier, and J. R. Mitchell, "Nearshore survey system evaluation," ERDC-CHL Vicksburg United States, Vicksburg, MS, USA, Tech. Rep. ERDC/CHL TR-17-19, 2017.

[44] P. S. Alexander and R. A. Holman, "Quantification of nearshore morphology based on video imaging," Mar. Geol., vol. 208, no. 1, pp. 101-111, Jul. 2004.

[45] C. Pianca, R. Holman, and E. Siegle, "Shoreline variability from days to decades: Results of long-term video imaging," J. Geophys. Res. C, Oceans, vol. 3, p. 120, Oct. 2015.

[46] K. L. Brodie et al., "Evaluation of video-based linear depth inversion performance and applications using altimeters and hydrographic surveys in a wide range of environmental conditions," Coast. Eng., vol. 136, pp. 147-160, Jun. 2018.

[47] R. Slocum, C. Parrish, R. K. Slocum, and C. E. Parrish, "Simulated imagery rendering workflow for UAS-based photogrammetric 3D reconstruction accuracy assessments," Remote Sens., vol. 9, no. 4, p. 396, Apr. 2017.

[48] T. N. Tonkin and N. G. Midgley, "Ground-control networks for image based surface reconstruction: An investigation of optimum survey designs using UAV derived imagery and structure-from-motion photogrammetry," Remote Sens., vol. 8, no. 9, p. 786, Sep. 2016.

[49] M. Conlin, N. Cohn, and P. Ruggiero, "A quantitative comparison of low-cost structure from motion (SfM) data collection platforms on beaches and dunes," J. Coast. Res., vol. 34, no. 6, pp. 1341-1351, Apr. 2018.

[50] R. Wackrow and J. H. Chandler, "Minimising systematic error surfaces in digital elevation models using oblique convergent imagery," Photogramm. Rec., vol. 26, no. 133, pp. 16-31, 2011.

[51] R. Wackrow and J. H. Chandler, "A convergent image configuration for DEM extraction that minimises the systematic effects caused by an inaccurate lens model," Photogramm. Rec., vol. 23, no. 121, pp. 6-18, Mar. 2008.

[52] M. I. Vousdoukas et al., "The role of combined laser scanning and video techniques in monitoring wave-by-wave swash zone processes," Coast. Eng., vol. 83, pp. 150-165, Jan. 2014.

[53] L. J. Moore, P. Ruggiero, and J. H. List, "Comparing mean high water and high water line shorelines: Should proxy-datum offsets be incorporated into shoreline change analysis?" J. Coast. Res., vol. 5, pp. 894-905, Jul. 2006.

[54] P. Ruggiero, G. M. Kaminsky, G. Gelfenbaum, P. Ruggierof, G. M. Kaminskyt, and G. Gelfenbaumf, "Linking proxy-based and datum-based shorelines on a high-energy coastline: Implications for shoreline change analyses," Source J. Coast. Res., vol. 5, pp. 57-82, Oct. 2003.

[55] B. Aerobotics. (2018). FireFly6 PRO Payload Flight Times. [Online]. Available: https://www.birdseyeview.aero/collections/payloads-pro

[56] E. Steiner. (2017). Drone Flight Stats-Part 1, AirData UAV. [Online]. Available: https://airdata.com/blog/2017/drone-flight-stats-part-1

[57] (2018). DJI Matrice 600 Specifications. [Online]. Available: https:// www.dji.com/matrice 600 


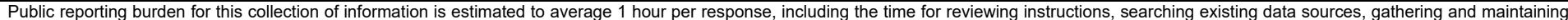

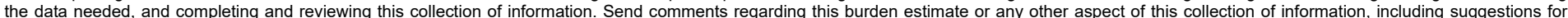

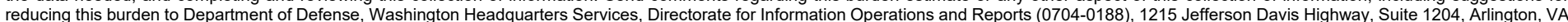

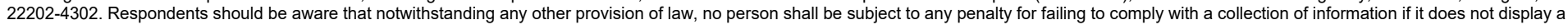
currently valid OMB control number. PLEASE DO NOT RETURN YOUR FORM TO THE ABOVE ADDRESS.
1. REPORT DATE (DD-MM-YYYY) 2. REPORT TYPE
August 2021 Final

\section{TITLE AND SUBTITLE}

Simultaneous Mapping of Coastal Topography and Bathymetry from a Lightweight Multicamera UAS

\section{DATES COVERED (From - To)}

5a. CONTRACT NUMBER

5b. GRANT NUMBER

5c. PROGRAM ELEMENT NUMBER

6. AUTHOR(S)

Katherine L. Brodie, Brittany L. Bruder, Richard K. Slocum, and Nicholas J. Spore

5d. PROJECT NUMBER

5e. TASK NUMBER

5f. WORK UNIT NUMBER

\section{PERFORMING ORGANIZATION NAME(S) AND ADDRESS(ES)}

U.S. Army Engineer Research \& Development Center

Coastal and Hydraulics Laboratory

Field Research Facility

3909 Halls Ferry Road

Vicksburg, MS 39180

School of Civil \& Construction Engineering

Oregon State University

Corvallis, OR 97331

\section{SPONSORING / MONITORING AGENCY NAME(S) AND ADDRESS(ES)}

U.S. Army Corps of Engineers

Washington, DC 20314

\section{DISTRIBUTION / AVAILABILITY STATEMENT}

Approved for public release; distribution is unlimited.

\section{SUPPLEMENTARY NOTES}

This article was originally published in IEEE Transactions on Geoscience and Remote Sensing, 27 August 2019.

This work was supported in part by the Deputy Assistant Secretary of the Army for Research and Technology under ERDC's research program titled "Force Projection Entry Operations, STO D.GRD.2015.34," in part by the USACE Department of Homeland Security Emergency Management Office, in part by the USACE Flood and Coastal Systems Program, and in part by the USACE Coastal Ocean Data Systems Program.

\section{ABSTRACT}

A low-cost multicamera Unmanned Aircraft System (UAS) is used to simultaneously estimate open-coast topography and bathymetry from a single longitudinal coastal flight. The UAS combines nadir and oblique imagery to create a wide field of view (FOV), which enables collection of mobile, long dwell timeseries of the littoral zone suitable for structure-from motion (SfM), and wave speed inversion algorithms. Resultant digital surface models (DSMs) compare well with terrestrial topographic lidar and bathymetric survey data at Duck, NC, USA, with root-mean-square error (RMSE)/bias of 0.26/-0.05 and 0.34/-0.05 m, respectively. Bathymetric data from another flight at Virginia Beach, VA, USA, demonstrates successful comparison (RMSE/bias of 0.17/0.06 m) in a secondary environment. UAS-derived engineering data products, total volume profiles and shoreline position, were congruent with those calculated from traditional topo-bathymetric surveys at Duck. Capturing both topography and bathymetry within a single flight, the presented multicamera system is more efficient than data acquisition with a single camera UAS; this advantage grows for longer stretches of coastline $(10 \mathrm{~km})$. Efficiency increases further with an on-board Global Navigation Satellite System-Inertial Navigation System (GNSS-INS) to eliminate ground control point (GCP) placement. The Appendix reprocesses the Virginia Beach flight with the GNSS-INS input and no GCPs.

\section{SUBJECT TERMS}

Coastal mapping, multiview stereo (MVS), nearshore morphology, remote sensing, structure from motion (SfM), Unmanned Aircraft Systems (UAS)

\section{SECURITY CLASSIFICATION OF:}

\section{a. REPORT}

Unclassified

\section{b. ABSTRACT}

Unclassified

\section{c. THIS PAGE}

Unclassified

\begin{tabular}{c|c}
$\begin{array}{c}\text { 17. LIMITATION } \\
\text { OF ABSTRACT }\end{array}$ & $\begin{array}{c}\text { 18. NUMBER } \\
\text { OF PAGES }\end{array}$ \\
UU & 26 \\
\hline
\end{tabular}

19a. NAME OF RESPONSIBLE PERSON

19b. TELEPHONE NUMBER (include area code) 